Article

\title{
Carbon Supported Multi-Branch Nitrogen-Containing Polymers as Oxygen Reduction Catalysts
}

\author{
Ya Chu ${ }^{1}$, Lin $\mathrm{Gu}^{1}{ }^{1}$, Xiuping $\mathrm{Ju}^{2}{ }^{2}$, Hongmei Du ${ }^{1}$, Jinsheng Zhao ${ }^{1, *(1)}$ and Konggang $\mathrm{Qu}{ }^{1, *(1)}$ \\ 1 Shandong Key Laboratory of Chemical Energy Storage and Novel Cell Technology, Liaocheng University, \\ Liaocheng 252059, China; chuyaya19950621@126.com (Y.C.); gulin124578@126.com (L.G.); \\ duhongmei@lcu.edu.cn (H.D.) \\ 2 Dongchang College, Liaocheng University, Liaocheng 252059, China; jxp1127@163.com \\ * Correspondence: j.s.zhao@163.com (J.Z.); kgqu1985@gmail.com (K.Q.); \\ Tel.: +86-635-853-9607 (J.Z.); +86-635-853-9077 (K.Q.)
}

Received: 13 May 2018; Accepted: 8 June 2018; Published: 12 June 2018

check for updates

\begin{abstract}
A composite catalyst was obtained by covalently linking G4- $\mathrm{NH}_{2}$ dendrimers and 1,10-phenanthroline-5-carboxylic acid on the surface of carbon powder, and the composite was named as PMPhen/C. In order to improve the catalytic performance of the composite, copper ions (II) were introduced to PMPhen/C by complex to form the PMPhen-Cu/C catalyst. Scanning electron microscope (SEM) and X-ray photoelectron spectroscopy (XPS) were applied to investigate the surface microstructure and elemental compositions of the catalysts. The results from electrochemical analysis show that PMPhen/C reduced oxygen to hydrogen peroxide $\left(\mathrm{H}_{2} \mathrm{O}_{2}\right)$ through a two-electron transfer process. PMPhen- $\mathrm{Cu} / \mathrm{C}$ could reduce oxygen to water through a four-electron pathway. Except the slightly lower initial reduction potential, $\mathrm{PMPhen}-\mathrm{Cu} / \mathrm{C}$ has a comparable oxygen reduction ability (ORR) to that of the commercially available Pt/C catalyst, which makes it a potential candidate as the cathodic catalyst in some fuel cells running in neutral medium, such as a microbial fuel cell.
\end{abstract}

Keywords: Polyamidoamine (PAMAM) G4-NH 2 dendrimers; phenanthroline; covalent link; ORR catalyst

\section{Introduction}

Fuel cells, as a type of green and clean energy device, have the characteristics of high energy density and highly efficient energy conversion and have attracted much attention from both research and commercial circles in the past few decades [1-3]. In the foreseeable future, the application of fuel cells can be extended to a number of fields, including traffic transportation, distributed power generation plants, portable battery chargers, etc.

One of the key factors that restricts the application of fuel cells is torpid ORR kinetics in the cathode oxygen reduction reaction [4]. Pt is the best selection as an ORR catalyst to expedite the ORR at the cathode, but the expensive prices and scarce resources restrict its large application in fuel cells [5-7]. Therefore, replacing platinum with an alternative oxygen reduction catalyst with rich resources, low price and superior performance is considered to be the most effective way to solve the above problems.

Significant progresses had been made on the study of high performance ORR catalysts in the past few decades, such as Pt-based alloys [8], non-precious metal alloys [9], metal-free catalyst [1,2], metal-organic frameworks (MOFs) [10] and transition-metal complexes with nitrogen-containing polymer supported on carbon nanomaterials (such as graphitic arrays, carbon nanotubes, graphene and porous carbons) $[11,12]$. Some of them showed comparable catalytic activities to that of commercially available $\mathrm{Pt} / \mathrm{C}$ and possessed the potentiality for commercialization [8-12]. According to the statistics of the existing literature, the non-platinum nitrogen-containing carbon materials are the hot topics 
in the current study of ORR catalysts [7]. Nitrogen and transition metals introduced in a certain way are considered to be key factors for the function of the ORR catalysts, which usually exist in the form of $\mathrm{M}-\mathrm{N}_{x}(\mathrm{M}=\mathrm{Fe}, \mathrm{Co}, \mathrm{Ni}, \mathrm{Mn}, \mathrm{Cu}$, etc. $)$ [13]. Meanwhile, the carbon materials were also frequently used as the supporting materials for the catalysts due to their high conductivity, porous microstructure and high specific surface area. The porous structure of carbon materials can not only increase the contact area between catalyst and oxygen, but also construct more channels for the diffusion of $\mathrm{O}_{2}, \mathrm{H}_{2} \mathrm{O}, \mathrm{H}_{2} \mathrm{O}_{2}$ and other additional intermediates and can be beneficial to improve the ORR activities of the catalysts [14]. Apart from providing supporting carbon material, another effective approach for improving the ORR activities of the catalysts was the pyrolysis of the $\mathrm{M}-\mathrm{N}_{x}$-containing materials under inert atmosphere, which is beneficial to the fixation and optimization of the structure of the M- $\mathrm{N}_{x}$ unit and then improving the stabilities of the catalysts [1,15]. The pyrolysis process is helpful for the doping of hetero atoms and transitional metal atoms on the surface of carbon materials, but the disadvantage is that the reaction of the doping process is unordered, which brings trouble to the quantitative analysis of the relationship between the ORR activities and the catalyst precursors. At present, the nitrogen-containing precursors include polypyrrole, porphyrins, polyphthalocyanines, polyaniline (PANI), phenanthroline (Phen), etc. [16-19].

Many reports adopt some of the nitrogen-containing heterocyclic ligands as the nitrogen source for the preparation of $\mathrm{M}-\mathrm{N}_{x}$-containing catalyst, and the $\mathrm{M}-\mathrm{N}_{x}$ unit has been considered as the active site of the catalysts, which were in the form of the non-pyrolysis state [20-22]. During the pyrolysis process, the complexing metal ions contributed to the improved ORR activity by promoting the formation of the types of doping nitrogen such as pyridine nitrogen and pyrrolic nitrogen, which was supposed to have higher ORR activities than that of graphitic and quaternary nitrogen [23].

Recently, we had prepared some composite catalysts formed between carbon materials and functionalized polymers, which were prepared by covalently linking nitrogen-containing heterocyclic ligands to polymers [24]. Then, the metal ions were also introduced to the composite catalysts by the complexation reaction between metal ions and the composites of polymer/carbon materials. This type of composite catalyst usually takes a predominant four-electron pathway for the reduction of oxygen $[25,26]$.

G4- $\mathrm{NH}_{2}$ dendrimers consist of a polybranched polymer with many amino groups. The amino group at the terminal can covalently link nitrogen-containing ligands, which can be used not only as a carrier of ORR active groups (such as $\mathrm{M}-\mathrm{N}_{x}$ ), but also as a source of nitrogen atoms for the preparation of ORR catalysts. In the present study, $\mathrm{G} 4-\mathrm{NH}_{2}$ dendrimer and 1,10-phenanthroline-5-carboxylic acid were linked covalently and then immobilized on the carbon powder, and the composite catalyst (PMPhen/C) for ORR was formed. In the subsequent step, the copper ion was introduced to the above composite and formed the PMPhen- $\mathrm{Cu} / \mathrm{C}$ catalyst. The reaction steps involved are shown in Scheme 1. During the whole synthesis steps, there was no any high temperature treatment, which aimed to keep the origin structure and element content of PMPhen- $\mathrm{Cu} / \mathrm{C}$, saving the cost of the finally-obtained catalysts. The surface microstructure and components were identified by means of scanning electron microscopy (SEM) and X-ray photoelectron spectroscopy (XPS). Furthermore, the ORR properties of the catalyst were quantitatively characterized by a set of electrochemical methods including cyclic voltammetry (CV), linear sweep voltammetry (LSV) rotating ring disk electrode (RRDE), etc. The results of this study confirm the slightly inferior oxygen reduction performance of the as-obtained catalyst compared to that of commercially available $\mathrm{Pt} / \mathrm{C}$ catalyst, which might be used in neutral medium fuel cells, such as microbial fuel cells.

\section{Result and Discussion}

\subsection{The Micro-Structured Surface and the Elemental Composition of the Catalysts}

As shown in Figure 1, the microstructure of Vulcan XC-72 carbon, PMPhen/C and PMPhen- $\mathrm{Cu} / \mathrm{C}$ were evaluated by scanning electron microscopy (SEM) images, respectively. It could be observed in 
Figure $1 \mathrm{a}$ that the carbon particles irregularly aggregate to form a porous structure, and the particle size is 35-60 nm. For PMPhen/C and PMPhen- $\mathrm{Cu} / \mathrm{C}$, the microstructure was the same as $\mathrm{C}$ (Vulcan XC-72), the only differences being that their particle size increased gradually along with the introduction of PMPhen and Cu-PMPhen, and the particle sizes were $40-60 \mathrm{~nm}$ and $40-65 \mathrm{~nm}$, respectively. This porous structure of PMPhen/C and PMPhen- $\mathrm{Cu} / \mathrm{C}$ can facilitate the mass transfer by providing more channels during ORR and ultimately improve the catalytic activity of the catalysts [27].

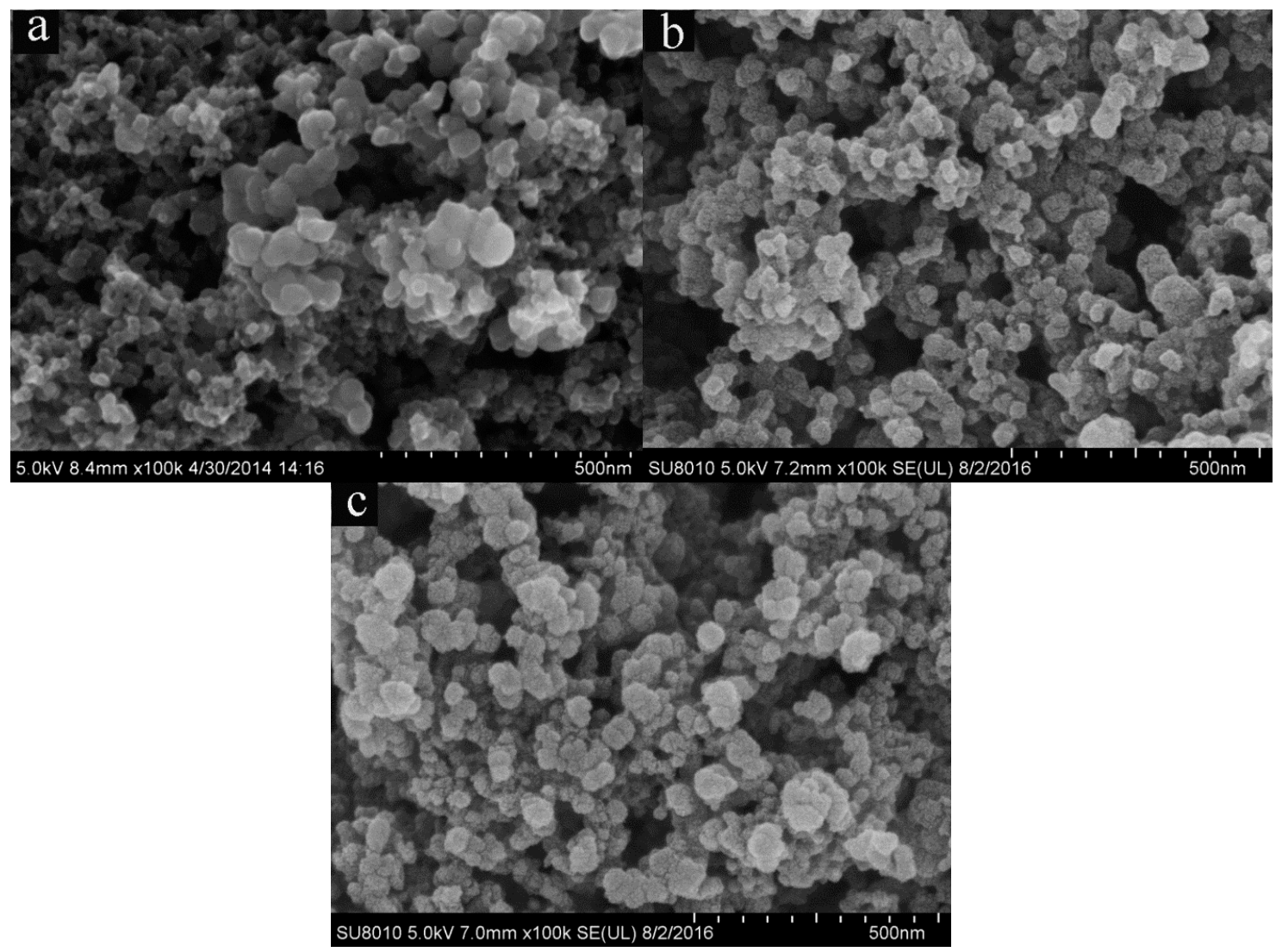

Figure 1. Scanning electron microscopy (SEM) images of C (Vulcan XC-72) (a), PMPhen/C (b) and PMPhen-Cu/C (c).

The microstructures and the structural changes during the formation of the catalyst composites were further monitored by the nitrogen adsorption analysis. The isotherms of three materials during the adsorption/desorption process of nitrogen gas are shown in Figure 2, and the subjected materials included carbon powder, PMPhen/C and PMPhen- $\mathrm{Cu} / \mathrm{C}$ composites. The parameters concerning the microstructures of the materials are listed in Table 1, which indicated the changes in the total surface area and the pore volumes of the materials. The apparent decrease in both of two parameters as shown in Table 1 for both PMPhen/C and PMPhen-Cu/C (relative to that of the carbon powder) illustrated the formation of the catalyst composites. 


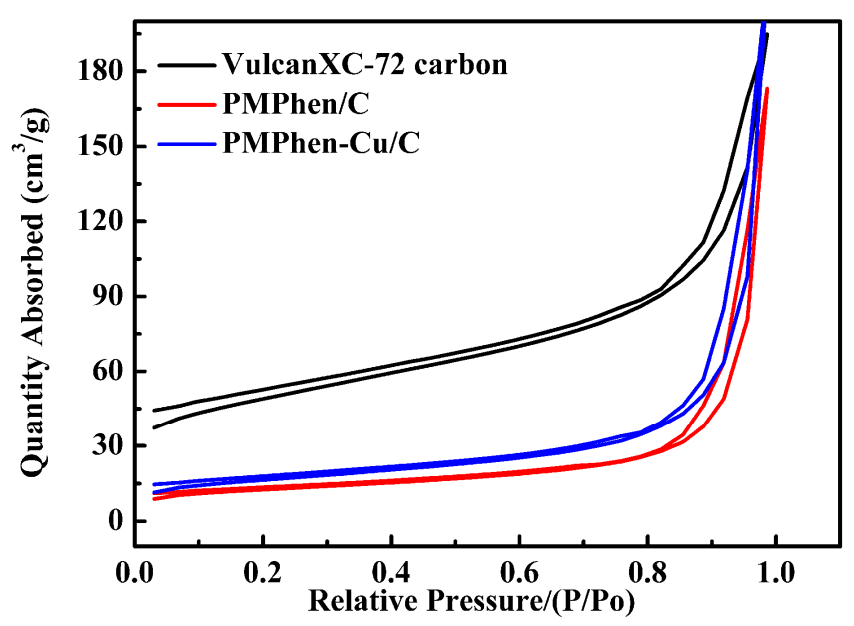

Figure 2. The isotherms of Vulcan XC-72 (black line), PMPhen/C (red line) and PMPhen-Cu/C (blue line) during the adsorption/desorption of nitrogen gas.

Table 1. The parameters obtained from the nitrogen adsorption/desorption of three materials.

\begin{tabular}{cccc}
\hline Samples and Parameters & Vulcan XC-72 Carbon & PMPhen/C & PMPhen-Cu/C \\
\hline BET Surface Area $\left(\mathrm{m}^{2} / \mathrm{g}\right)$ & 166.67 & 42.96 & 56.58 \\
Pore Volume $\left(\mathrm{cm}^{3} / \mathrm{g}\right)$ & 0.3 & 0.26 & 0.27 \\
\hline
\end{tabular}

X-ray photoelectron spectroscopy (XPS) measurements were taken for both PMPhen/C and PMPhen- $\mathrm{Cu} / \mathrm{C}$ catalysts with the aim to analyze the components and the elemental states on the surface of the catalysts. Figure 3 shows the $\mathrm{O} 1 \mathrm{~s}$ and the $\mathrm{N} 1$ s of the PMPhen/C composite. As depicted in Figure 3a, the O 1s spectrum of PMPhen/C consisted of two kinds of different peaks with different binding energies, which were ascribed to $\mathrm{O}=\mathrm{C}-\mathrm{N}(531.9 \mathrm{eV})$ and $\mathrm{Ph}-\mathrm{C}=\mathrm{O}(535.3 \mathrm{eV})$, respectively $[28,29]$. Figure $3 \mathrm{~b}$ shows the $\mathrm{N} 1 \mathrm{~s}$ spectrum of $\mathrm{PMPhen} / \mathrm{C}$, specifically the pyridinic-N had a binding energy of $399.6 \mathrm{eV}$, and another peak at $402.0 \mathrm{eV}$ could be ascribed to amine- $\mathrm{N}$ [30,31]. The presence of two kinds of nitrogen atoms and two kinds of oxygen atoms suggested the attachment of the 1,10-phenanthroline-5-carboxylic acid to the $\mathrm{G}_{4}-\mathrm{NH}_{2}$ dendrimer and finally confirmed the formation of the PMPhen/C composite. The survey scans of the two catalyst composites are shown in Figure 4, and an additional copper element was found in the PMPhen- $\mathrm{Cu} / \mathrm{C}$ composite besides its commonly owned elements including F, N, O and C elements, which suggested the successful formation of the PMPhen- $\mathrm{Cu} / \mathrm{C}$ composite by the complexation of copper ion (II) to the PMPhen/C composite. The atomic abundance of the $\mathrm{Cu}$ ion on the surface of the catalyst of PMPhen-Cu was $0.78 \%$, as obtained from the survey scan. The $\mathrm{O} 1 \mathrm{~s}$ spectrum for PMPhen- $\mathrm{Cu} / \mathrm{C}$ was also fitted with two contributions, and the binding energies of the two peaks were $532.0 \mathrm{eV}$ and $535.3 \mathrm{eV}$, respectively, without obvious changes compared to that of PMPhen/C, suggesting that oxygen atoms did not participate in the complexation reaction (Figure 5a). Compared to PMPhen/C, the $\mathrm{N} 1 \mathrm{~s}$ peaks of PMPhen-Cu/C shifted to higher binding energy at $400.2 \mathrm{eV}$ and $402.2 \mathrm{eV}$ for pyridinic- $\mathrm{N}$ and amine- $\mathrm{N}$, respectively, which suggested the formation of the complexation between $\mathrm{Cu}^{2+}$ and pyridinic-N (Figure 5b) [32]. The formation of the PMPhen- $\mathrm{Cu} / \mathrm{C}$ could be directly confirmed by the presence of the complexed copper ion in the composite. As depicted in Figure 5c, the peaks at the binding energies of $935.4 \mathrm{eV}$ and $955.7 \mathrm{eV}$ were ascribed to the $\mathrm{Cu} 2 \mathrm{p}_{3 / 2}$ and $\mathrm{Cu} 2 \mathrm{p}_{1 / 2}$ of the complex state copper $\left(\mathrm{Cu}-\mathrm{N}_{x}\right)$, respectively [33]. Meanwhile, the peak at the binding energy of 942.3 was a satellite peak of the complexed $\mathrm{Cu}^{2+}$ in the composite [34]. Another couple of peaks were also found at $932.9 \mathrm{eV}$ and $953.2 \mathrm{eV}$, suggesting the presence of dissociative copper in the composite, which might be absorbed by the carbon matrix [35]. Based on the above analysis, a conclusion could be made that the composites including PMPhen/C and PMPhen-Cu/C had been successfully obtained. 

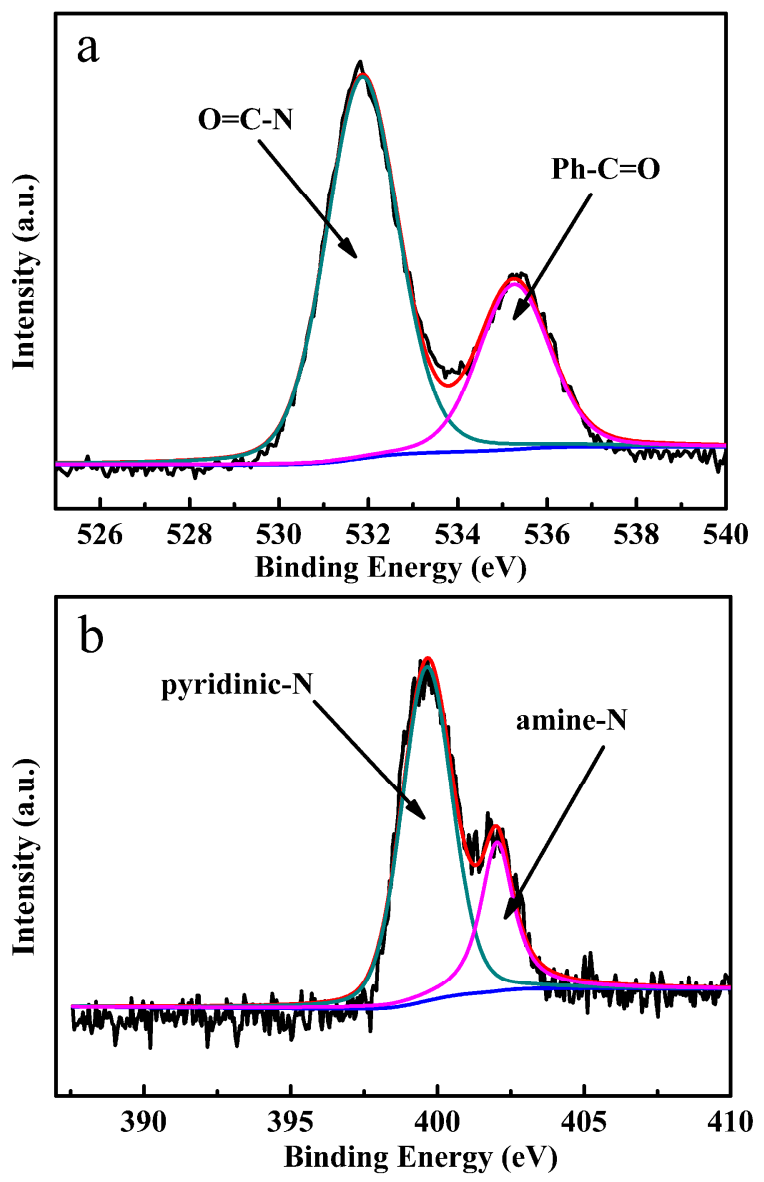

Figure 3. The X-ray photoelectron spectroscopy (XPS) spectra of the $\mathrm{O} 1 \mathrm{~s}$ spectrum (a) and $\mathrm{N} 1 \mathrm{~s}$ spectrum (b) of the PMPhen/C composite.
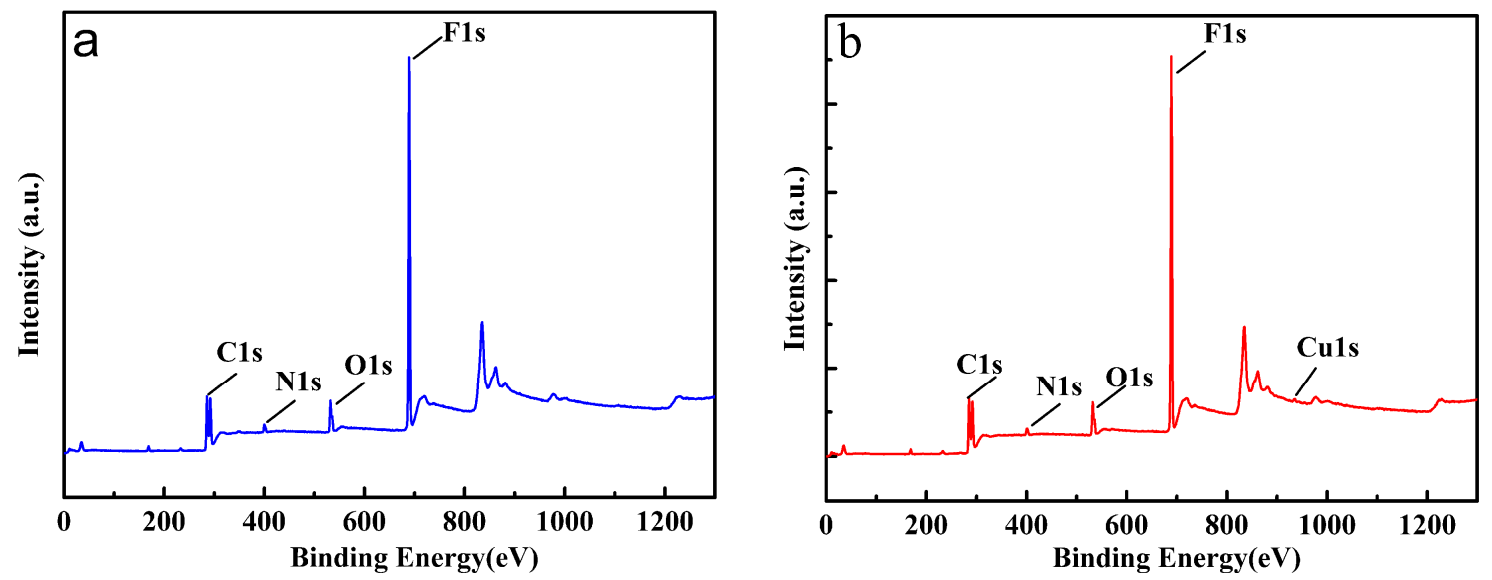

Figure 4. The X-ray photoelectron spectroscopy (XPS) survey scans of PMPhen/C (a) and PMPhen-Cu/C (b) composites. 

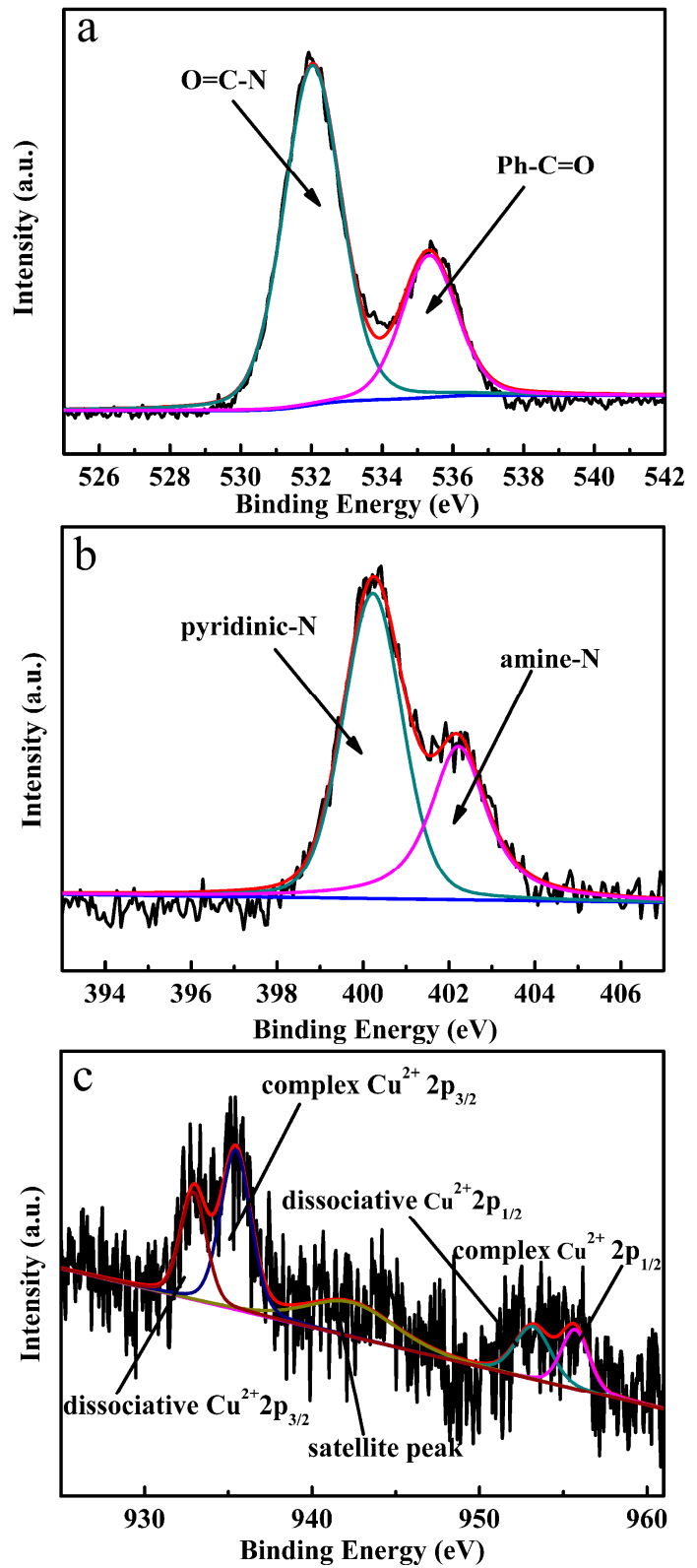

Figure 5. The X-ray photoelectron spectroscopy (XPS) spectra of O 1s (a), N 1s (b) and Cu 2p (c) for the PMPhen- $\mathrm{Cu} / \mathrm{C}$ composite.

\subsection{Electrocatalytic Characterization and Catalyst's Study of Dynamics}

Figure 6 shows the cyclic voltammetry (CV) curves of PMPhen/C and PMPhen- $\mathrm{Cu} / \mathrm{C}$, respectively, which was measured in $0.1 \mathrm{M}$ phosphate buffer solution(PBS) saturated with nitrogen or oxygen. As indicated in Figure 6a, the voltammogram of PMPhen/C shows a nearly quasi-rectangular shape with a couple of minor redox peaks located at $E_{\text {red }}=0.59 \mathrm{~V}$ and $E_{\text {oxy }}=0.63 \mathrm{~V}$, respectively, which was tested in nitrogen-saturated electrolyte. In the case of the oxygen-saturated electrolyte, a well-defined reduction peak was observed at $0.15 \mathrm{~V}$ vs. reversible hydrogen electrode (RHE), and the reduction current was $-0.23 \mathrm{~mA}$, which was much higher than the reduction current obtained in the nitrogen-saturated electrolyte. The above difference in the voltammograms indicated the presence of the ORR activity for the PMPhen/C composite. The cyclic voltammetry (CV) curve of PMPhen- $\mathrm{Cu} / \mathrm{C}$ (Figure $6 \mathrm{~b}$ ) measured in nitrogen saturated electrolyte showed a couple of dissymmetric redox peaks at $0.37 \mathrm{~V} / 0.64 \mathrm{~V}$ vs. RHE, which might be related to the redox switch of the $\mathrm{Cu}^{+} / \mathrm{Cu}^{2+}$ 
redox couple [36,37]. Notably, the reduction currents increased rapidly from $-0.36 \mathrm{~mA}--0.58 \mathrm{~mA}$, when the bubbling gas was changed from nitrogen gas to oxygen gas, with the reduction potential remaining unchanged in this process. The increase in reduction current was up to $0.22 \mathrm{~mA}$, which might be attributed to the ORR activity occurring on electrode surface catalyzed by the PMPhen-Cu/C composite as the catalyst. For the sake of comparisons, the cyclic voltammetry $(\mathrm{CV})$ of $\mathrm{Pt} / \mathrm{C}$ was also recorded in $0.1 \mathrm{M}$ PBS saturated with oxygen from $0 \mathrm{~V}-1.19 \mathrm{~V}$, which is presented in Figure $6 \mathrm{c}$, together with that of the PMPhen- $\mathrm{Cu} / \mathrm{C}$ and the PMPhen/C catalysts. Obviously, the reduction peak potential of PMPhen- $\mathrm{Cu} / \mathrm{C}$ was more positive and the reduction current was larger than that of the PMPhen/C composite. Thus, copper ions played a pivotal role in enhancing the electrochemical behaviors, and it may act as a catalytic site for ORR. Compared with $\mathrm{Pt} / \mathrm{C}$, PMPhen- $\mathrm{Cu} / \mathrm{C}$ had lower reduction potential and higher reduction current, which suggested that PMPhen- $\mathrm{Cu} / \mathrm{C}$ had the advantage in some aspects as an ORR catalyst.
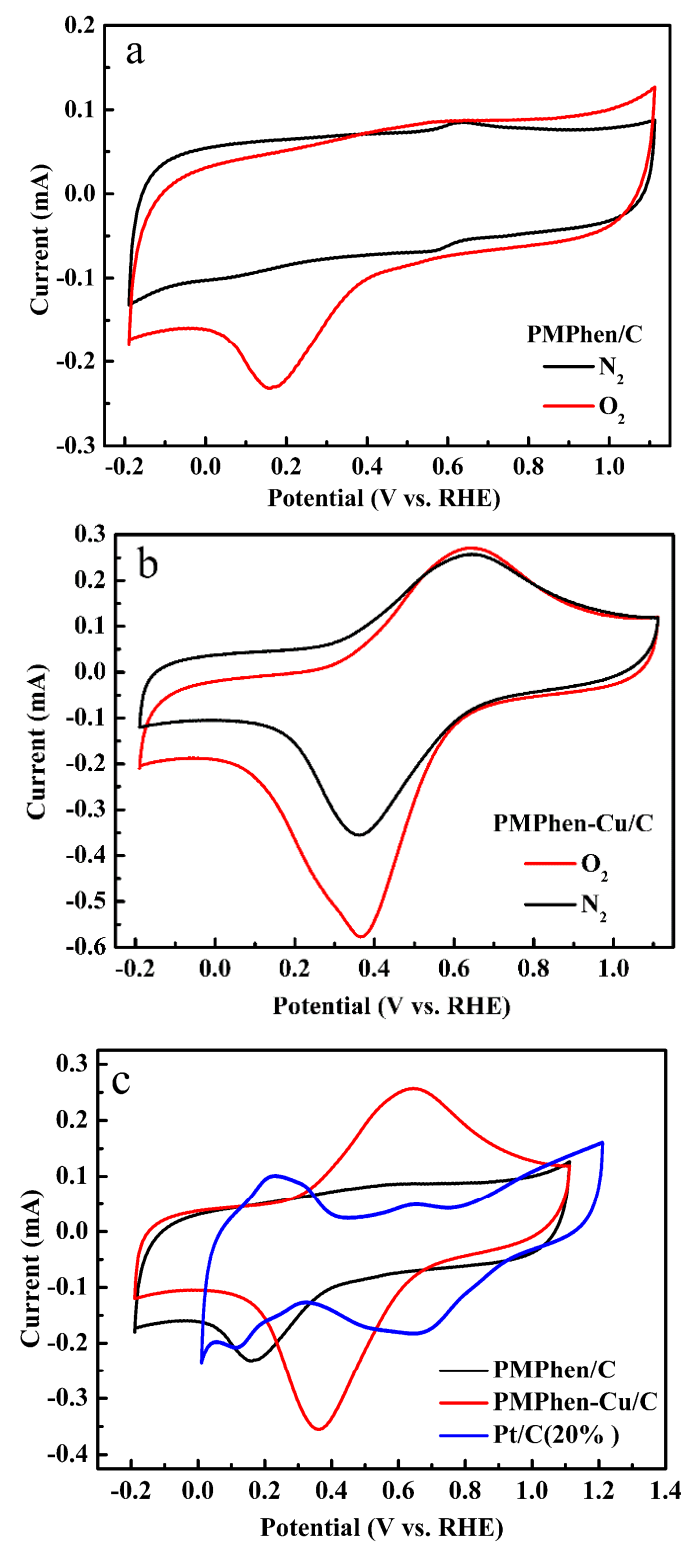

Figure 6. Cyclic voltammetry (CV) curves of PMPhen/C (a) and PMPhen-Cu/C (b) in nitrogen and oxygen-saturated electrolyte; CV curve of PMPhen/C, PMPhen-Cu/C and $\mathrm{Pt} / \mathrm{C}(20 \% \mathrm{Pt}$ content) measured in oxygen saturated electrolyte (c). Scan rate: $100 \mathrm{mV} / \mathrm{s}$. 
The stability of the catalyst is a crucial issue that must be paid enough attention for the realization of its practical applications. Continuous cyclic voltammetry (CV) scans up to 500 cycles were conducted for the persistence evaluation of two catalysts (Figure 7). The retention of the oxygen reduction peaks was used for the quantitative analysis and comparison of the stabilities of the catalysts. At the 500th scan, the retention rates of the reduction currents were $94.9 \%$ and $94.2 \%$, for PMPhen/C and PMPhen- $\mathrm{Cu} / \mathrm{C}$ composites, respectively, which indicated the acceptable stabilities for industrial applications as cathodic catalyst.
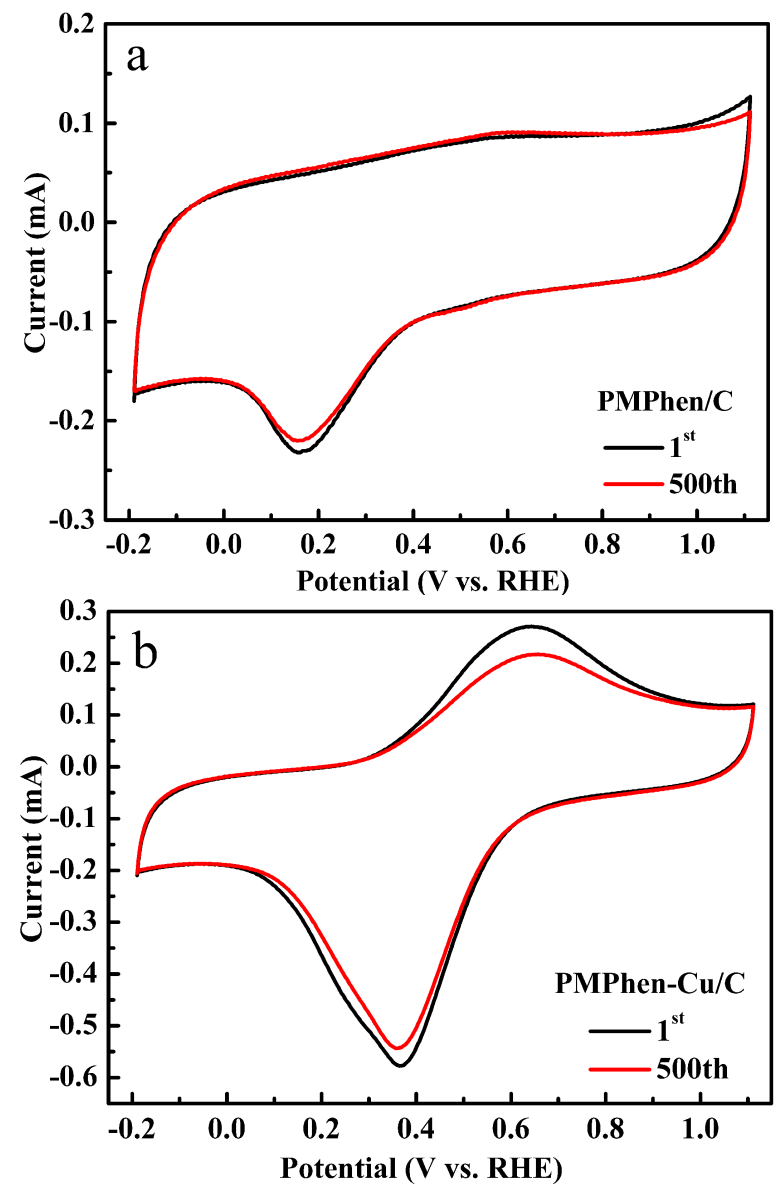

Figure 7. Repeated cyclic voltammetry (CV) curves of PMPhen/C (a) and PMPhen-Cu/C (b) measured in oxygen-saturated electrolyte for stability tests. Scan rate: $100 \mathrm{mV} / \mathrm{s}$.

With the aim to obtain the ORR activity of PMPhen/C and PMPhen-Cu/C quantitatively, the rotating disk electrode (RDE) measurements of PMPhen $/ \mathrm{C}$, PMPhen- $\mathrm{Cu} / \mathrm{C}$ and $\mathrm{Pt} / \mathrm{C}$ were taken at a scan rate of $10 \mathrm{mV} / \mathrm{s}$. The linear sweep voltammetry (LSV) curves of PMPhen/C and PMPhen-Cu/C at various rotating rates are shown in Figure $8 \mathrm{a}, \mathrm{b}$, respectively. Furthermore, the linear sweep voltammetry (LSV) curve of commercially available Pt/C (20\% Pt content) is given in Figure S1 (see the Supplementary Materials) for comparison purposes. The LSV curves of three catalysts were similar to each other in shape, and the differences were in the different initial reduction potential values $\left(E_{\text {onset }}\right)$ and the different limiting diffusion currents $\left(I_{\mathrm{dl}}\right)$ at the varied rotation speeds. For each of the catalyst, the $I_{\mathrm{dl}}$ values increase accordingly with the increase of the rotating speeds, and the $E_{\text {onset }}$ values of each catalyst remain unchanged. The LSV curve of the ORR catalyst could be divided into three distinct regions, with one being the kinetic current region locating in the middle slash area of the " $\mathrm{S}$ " shaped LSV curve, one being the diffusion control region at the platform area and the third region being the mixed control area located at the junction of the above two regions. From the linear sweep voltammetry (LSV) curves shown in Figure 8 and Figure S1, the parameters were obtained, the $E_{\text {onset }}$ values were 
$0.45 \mathrm{~V}, 0.61 \mathrm{~V}$ and $0.9 \mathrm{~V}$, respectively, for PMPhen/C, PMPhen-Cu/C and Pt/C (20\% Pt content). At the rotation rate of $1600 \mathrm{rpm} / \mathrm{min}$, the current densities were $-2.44 \mathrm{~mA} / \mathrm{cm}^{2},-4.53 \mathrm{~mA} / \mathrm{cm}^{2}$ and $-4.94 \mathrm{~mA} / \mathrm{cm}^{2}$, respectively, for PMPhen/C, PMPhen-Cu/C and Pt/C (20\% Pt content) (Figure 8c). Through the analysis of the above data, it is clear that the $\mathrm{Pt} / \mathrm{C}$ had the most superior ORR activity among the three catalysts, which was followed by PMPhen- $\mathrm{Cu} / \mathrm{C}$ and PMPhen/C catalyst in turn. In addition, taking the different ORR activities between PMPhen- $\mathrm{Cu} / \mathrm{C}$ and PMPhen/C, it is clear that the complexation of copper ions to PMPhen/C could greatly improve the ORR performance of the obtained ORR catalyst.
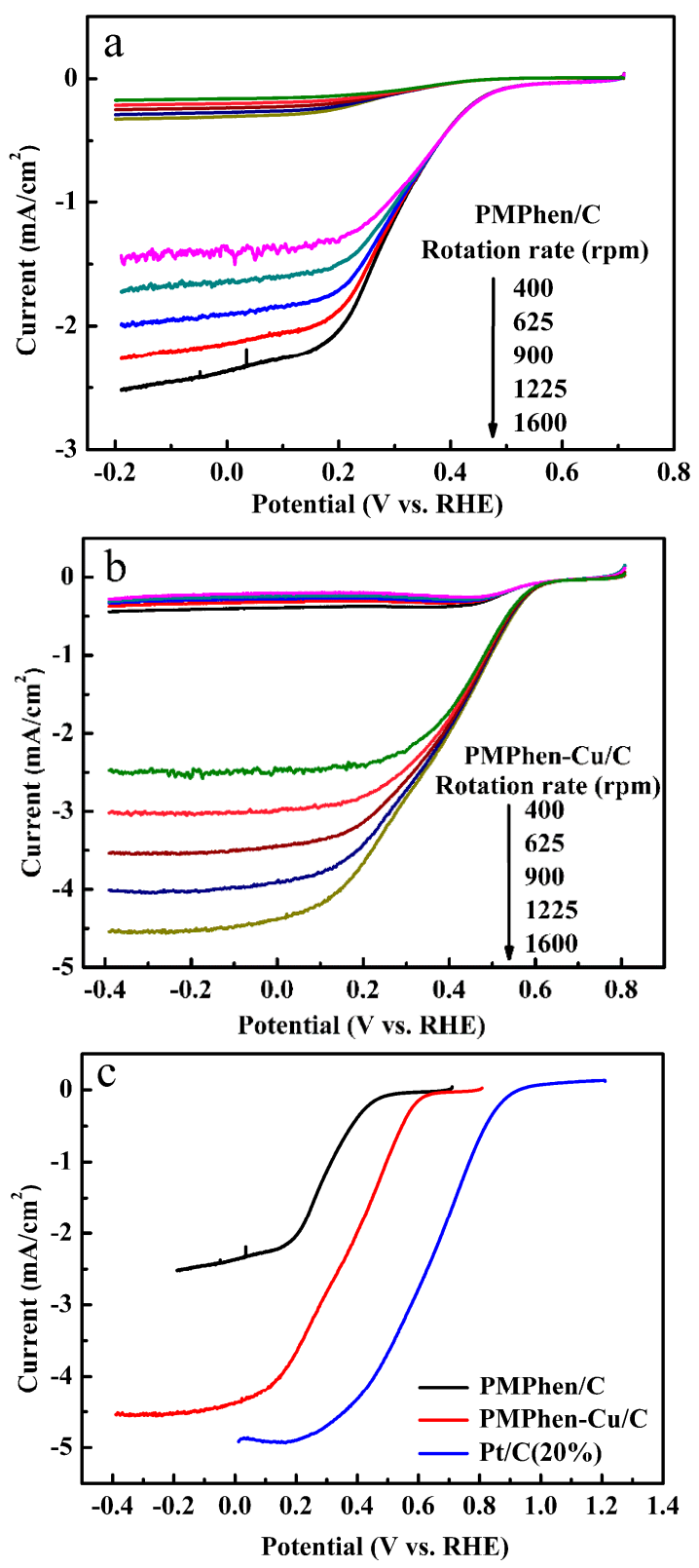

Figure 8. Linear sweep voltammetry (LSV) of PMPhen/C (a) and PMPhen-Cu/C (b) at different rotating speeds in oxygen-saturated electrolyte; and (c) LSV curve of PMPhen/C, PMPhen-Cu/C and $\mathrm{Pt} / \mathrm{C}(20 \% \mathrm{Pt}$ content) at a rotating speed of $1600 \mathrm{rpm}$. Scan rate: $10 \mathrm{mV} / \mathrm{s}$.

The number of electrons involved in the oxygen reduction process was directly related to the reduction mechanism of the catalysts. The four-electron pathway has been considered the most preferable pathway, in which oxygen is directly reduced to water, giving a high open circuit voltage 
of the fuel cells. In the two-electron reduction pathway, oxygen is reduced to hydrogen peroxide, which has a strong corrosion effect on the electrode and the diaphragm, so the pathway has been considered as a more unfavorable ORR pathway.

The rotating disk electrode (RDE) data were used to construct the Koutecky-Levich (K-L) plots on account of the Koutecky-Levich Equations (1) and (2) as below [37]. The $i_{d}$ in Equation (1) refers to the current density of the disk electrode.

$$
\begin{gathered}
1 / i_{d}=1 / i_{k}+1 / i_{d l} \\
i_{d l}=B \omega^{1 / 2}=0.62 n F C_{o} D_{o}{ }^{2 / 3} v^{-1 / 6} \omega^{1 / 2}
\end{gathered}
$$

where $i_{k}$ is the kinetic current density and $i_{d l}$ is the diffusion-limiting current density, which could be calculated by Equation (2). In the Equation (2), $\omega$ is the angular velocity of the rotating electrode, $C_{o}$ is the oxygen concentration in the electrolyte, $D_{o}$ is the diffusion coefficient of oxygen and $v$ is the kinematic viscosity of the electrolyte. The Koutecky-Levich (K-L) plots of PMPhen/C, PMPhen-Cu/C and $\mathrm{Pt} / \mathrm{C}$ are shown in Figure $9 \mathrm{a}, \mathrm{b}$ and Figure S2, respectively, and there were apparent linear relationships at the selected potentials. The electron transfer number (n) can be calculated from the slope of the K-L plots, and the average n values were 2.4, 3.9 and 4.0, respectively, for the PMPhen/C, the PMPhen- $\mathrm{Cu} / \mathrm{C}$ and the $\mathrm{Pt} / \mathrm{C}$ catalysts. Thus, PMPhen $/ \mathrm{C}$ reduced oxygen to hydrogen peroxide by the two-electron pathway. Similar to the $\mathrm{Pt} / \mathrm{C}$ catalyst, oxygen was reduced by the PMPhen- $\mathrm{Cu} / \mathrm{C}$ catalyst to water through a four-electron transfer pathway. The rotating disk electrode (RDE) results quantitatively showed that the ORR activity of PMPhen-Cu/C was much higher than that of the catalyst PMPhen/C due to the complexation of copper ion to the latter catalyst.
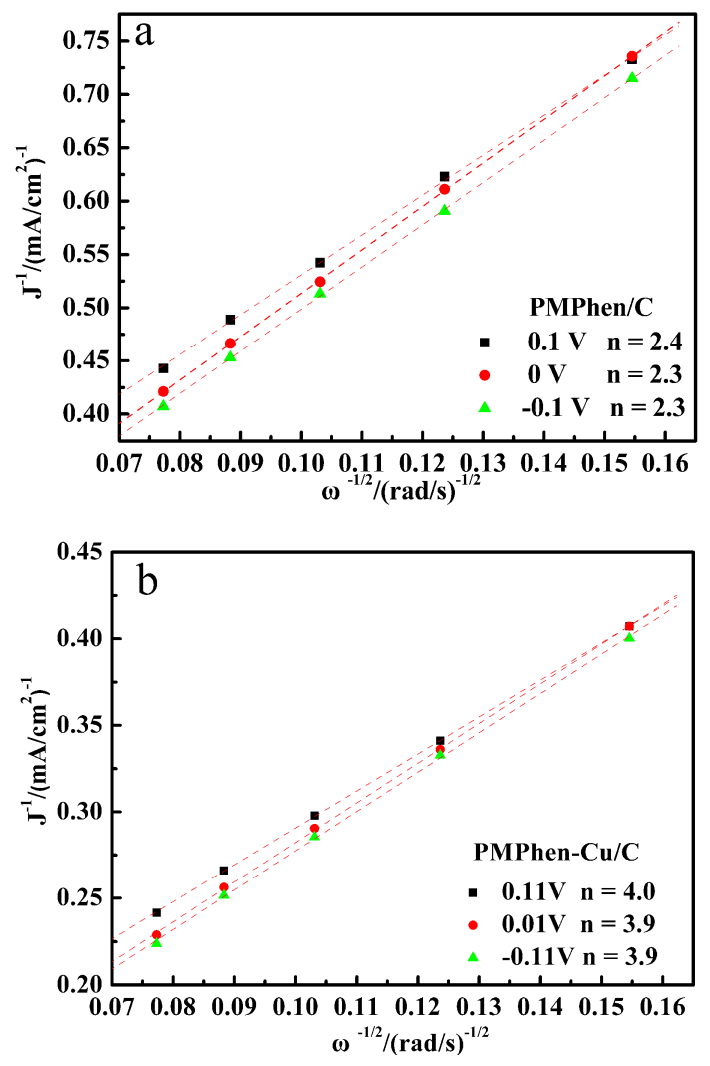

Figure 9. (a) Koutecky-Levich (K-L) plots of PMPhen/C at a potential of $0.1 \mathrm{~V}, 0 \mathrm{~V}$ and $-0.1 \mathrm{~V}$ and (b) K-L plots of PMPhen-Cu/C at a potential of $0.11 \mathrm{~V}, 0.01 \mathrm{~V}$ and $-0.11 \mathrm{~V}$. 
In aqueous solution, the copper ions complexed with phenanthroline unit might be introduced with two hydroxyl groups as the additional ligands to maintain the electrical neutrality of the composite, and the proposed structure of the complex is shown in Figure 10. The ORR mechanism could be assumed based on the mono- $\mathrm{Cu}$ reaction mechanism, which was also called the inner-sphere mechanism, proposed by Lei and Anson et al. [38]. The ORR process of PMPhen-Cu/C could be expressed by the following equations:

$$
\begin{gathered}
{\left[L C u^{I I}\left(\mathrm{OH}^{-}\right)_{2}\right]^{0}+e^{-} \rightleftharpoons\left[L C u^{I}\left(\mathrm{OH}^{-}\right)\right]^{0}+\mathrm{OH}^{-}} \\
{\left[L C u^{I}\left(\mathrm{OH}^{-}\right)\right]^{0}+\mathrm{O}_{2} \rightleftharpoons\left[L C u^{I I}\left(\mathrm{OH}^{-}\right)-\mathrm{O}_{2}^{-}\right]^{0}} \\
{\left[L C u^{I I}\left(\mathrm{OH}^{-}\right)-\mathrm{O}_{2}^{-}\right]^{0}+e^{-} \rightleftharpoons\left[L C u^{I I}-\mathrm{O}_{2}^{2-}\right]^{0}+\mathrm{OH}^{-}} \\
{\left[L C u^{I I}-\mathrm{O}_{2}^{2-}\right]^{0}+\mathrm{H}_{2} \mathrm{O} \rightleftharpoons\left[L C u^{I I}\left(O H^{-}\right)-\mathrm{O}_{2} \mathrm{H}^{-}\right]^{0}} \\
{\left[L C u^{I I}\left(O H^{-}\right)-\mathrm{O}_{2} \mathrm{H}^{-}\right]^{0}+2 e^{-}+3 \mathrm{H}_{2} \mathrm{O} \rightarrow\left[L C u^{I I}\left(O H^{-}\right)_{2}\right]^{0}+2 \mathrm{H}_{2} \mathrm{O}+2 O H^{-}}
\end{gathered}
$$

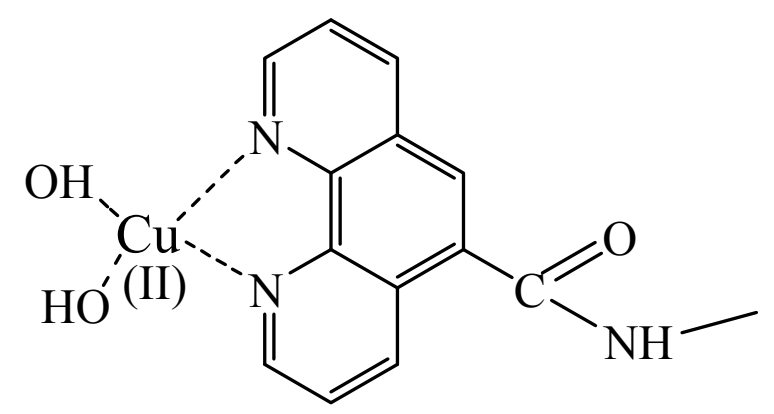

Figure 10. The proposed structure for the phenanthroline-Cu complex in aqueous solution.

According to the mechanism, $\mathrm{Cu}^{2+}-\mathrm{N}_{x}$ was the active site for the ORR activity of the composite, and all steps of the ORR process were carried out around this unit. The reduction of $\mathrm{Cu}^{2+}$ occurred in Equation (3), which was followed by the binding of oxygen molecular and the formation of the $\mathrm{Cu}^{2+}$-superoxide intermediate (Equation (4)). The product in Equation (4) was further reduced to $\mathrm{Cu}^{2+}$-peroxide species (Equation (5)), which was then protonated in the aqueous solution (Equation (6)). The deep reduction and the protonation of the product in Equation (6) occurred in a way as depicted in Equation (7), which was simultaneously accompanied by the release of water in an indeterminate number of steps.

$$
\begin{gathered}
\mathrm{O}_{2}+4 \mathrm{H}^{+}+4 e^{-} \stackrel{k_{1}}{\rightarrow} 2 \mathrm{H}_{2} \mathrm{O} \\
\mathrm{O}_{2}+2 \mathrm{H}^{+}+2 e^{-} \stackrel{k_{2}}{\rightarrow} \mathrm{H}_{2} \mathrm{O}_{2} \\
\mathrm{H}_{2} \mathrm{O}_{2}+2 \mathrm{H}^{+}+2 e^{-} \stackrel{k_{3}}{\rightarrow} 2 \mathrm{H}_{2} \mathrm{O}
\end{gathered}
$$

The ORR process is not a simple two-electron pathway or four-electron pathway, being actually a complicated and mixed mode in most cases, as shown in Figure 11. For example, the ORR process with an $\mathrm{n}$ value of four may include two distinct pathways: one is the direct four-electron pathway (Equation (8)), and the other includes two continuous two-electron process. Specifically, in the latter pathway, oxygen is first reduced to hydrogen peroxide (Equation (9)) and then reduced to water subsequently (Equation (10)). Rotating ring disk electrode (RRDE) voltammetry could provide detailed information of the ORR mechanism of the catalyst by giving the values of $k_{1}, k_{2}$ and $k_{3}$. 


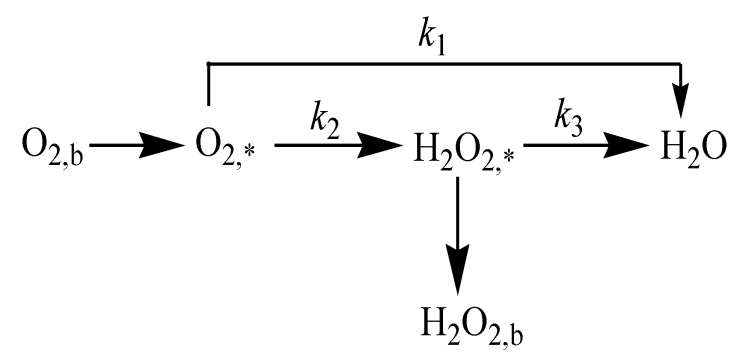

Figure 11. The available routes for ORR. $b$ and * refer to the bulk solution substance and electrode surface substance, respectively.

To verify the electron transfer number computed by rotating disk electrode (RDE) data and acquire the percentage of $\mathrm{H}_{2} \mathrm{O}_{2}$, the rotating ring disk electrode (RRDE) measurements at various rotating rates were undertaken at a scanning rate of $10 \mathrm{mV} / \mathrm{s}$. The ring potential was set to be $0.6 \mathrm{~V}$ (vs. $\mathrm{Ag} / \mathrm{AgCl}$ ) to ensure all $\mathrm{H}_{2} \mathrm{O}_{2}$ produced at the disk electrode was reduced to water at the ring electrode. The rotating ring disk electrode (RRDE) voltammetry curves of three catalysts including PMPhen/C, PMPhen- $\mathrm{Cu} / \mathrm{C}$ and $\mathrm{Pt} / \mathrm{C}$ are shown in Figure 12a-c, respectively, in which the upper part of the curve is the ring current, and the lower part is the disk current. The ring current of PMPhen/C is more than ten-times larger than that of PMPhen- $\mathrm{Cu} / \mathrm{C}$ or $\mathrm{Pt} / \mathrm{C}$. Meanwhile, the ring current of PMPhen- $\mathrm{Cu} / \mathrm{C}$ is nearly equal to that of the $\mathrm{Pt} / \mathrm{C}$ catalyst, which is far smaller than their respective disk currents. It is obvious that the $\mathrm{H}_{2} \mathrm{O}_{2}$ production percentage $\left(\mathrm{X}_{\mathrm{H} 2 \mathrm{O} 2}\right)$ detected at the ring elected for PMPhen/C is much higher than that of PMPhen- $\mathrm{Cu} / \mathrm{C}$ and $\mathrm{Pt} / \mathrm{C}$, respectively. The onset oxygen potential $\left(E_{\text {onset }}\right)$ and limiting diffusion currents at a rotating rate of $1600 \mathrm{rpm}$ were $0.5 \mathrm{~V}$ and $-0.33 \mathrm{~mA} / \mathrm{cm}^{2}, 0.62 \mathrm{~V}$ and $-4.6 \mathrm{~mA} / \mathrm{cm}^{2}, 0.90 \mathrm{~V}$ and $-5 \mathrm{~mA} / \mathrm{cm}^{2}$ for PMPhen $/ \mathrm{C}$, PMPhen- $\mathrm{Cu} / \mathrm{C}$ and $\mathrm{Pt} / \mathrm{C}$, respectively, which is consistent with the data obtained from the above RDE measurement. The $n$ value and the $\mathrm{X}_{\mathrm{H} 2 \mathrm{O} 2}$ value could be calculated by the next equation as below [39].

$$
\begin{gathered}
n=\frac{4 I_{d}}{I_{d}+\left(I_{r} / N\right)} \\
\% \mathrm{H}_{2} \mathrm{O}_{2}=\frac{200 I_{r} / N}{I_{d}+\left(I_{r} / N\right)}
\end{gathered}
$$

where $\mathrm{N}$ is the collection efficiency (43\%) of $\mathrm{H}_{2} \mathrm{O}_{2}$ and $I_{r}$ and $I_{d}$ are the limiting ring current and the limiting disk current, respectively. As shown in Figure 13a,b, the $\mathrm{X}_{\mathrm{H} 2 \mathrm{O} 2}$ values in the potential range of $-0.3 \mathrm{~V}-0.3 \mathrm{~V}$ were $62-76 \%$ and $1.5-4.5 \%$ for PMPhen/C and PMPhen- $\mathrm{Cu} / \mathrm{C}$, respectively. In addition, the $\mathrm{X}_{\mathrm{H} 2 \mathrm{O} 2}$ values continuously increased for both catalysts with the increase of the potential. In comparison, the plot for the $\mathrm{X}_{\mathrm{H} 2 \mathrm{O} 2}$ value vs. potential for the $\mathrm{Pt} / \mathrm{C}$ catalyst is also shown in Figure $13 \mathrm{c}$, which is $1-2.5 \%$ in the potential range of $0.1 \mathrm{~V}-0.7 \mathrm{~V}$. In addition, the $\mathrm{n}$ values for PMPhen/C, PMPhen- $\mathrm{Cu} / \mathrm{C}$ are also shown in Figure 14. For the PMPhen- $\mathrm{Cu} / \mathrm{C}$ catalyst, the $\mathrm{n}$ values were maintained at about four at the potential range of $-0.3 \mathrm{~V}-+0.3 \mathrm{~V}$ (vs. RHE), which indicated that the PMPhen- $\mathrm{Cu} / \mathrm{C}$ could catalyze a four-electron oxygen reduction process. The $\mathrm{n}$ value for PMPhen/C was about 2.5 and slightly increased as the potentials increased from $-0.3 \mathrm{~V}-0.3 \mathrm{~V}$, which indicated a predominant two-electron pathway. The results from both the RDE and the RRDE experiments uniformly suggested that the ORR activity of PMPhen- $\mathrm{Cu} / \mathrm{C}$ was much higher than that of PMPhen/C, which further shows that the copper ions played an essential effect in the process of oxygen reduction. Except the $E_{\text {onset }}$ potential, the catalysts of PMPhen- $\mathrm{Cu} / \mathrm{C}$ and $\mathrm{Pt} / \mathrm{C}$ had similar ORR activities in terms of $\mathrm{n}$ and $\mathrm{X}_{\mathrm{H} 2 \mathrm{O} 2}$ values. 

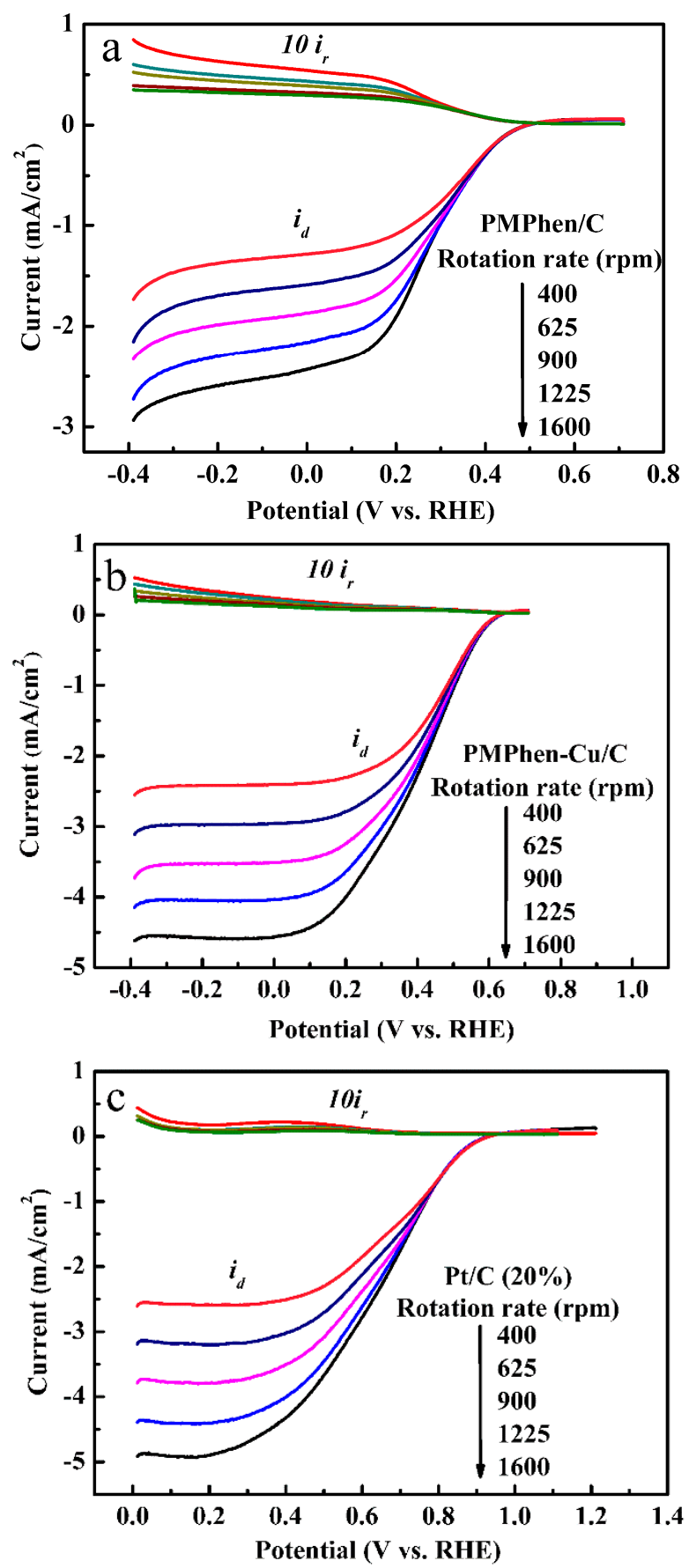

Figure 12. Rotating ring disk electrode (RRDE) curves of PMPhen/C (a), PMPhen-Cu/C (b) and Pt/C (20\% Pt content) (c). Scan rate: $10 \mathrm{mV} / \mathrm{s}$. 

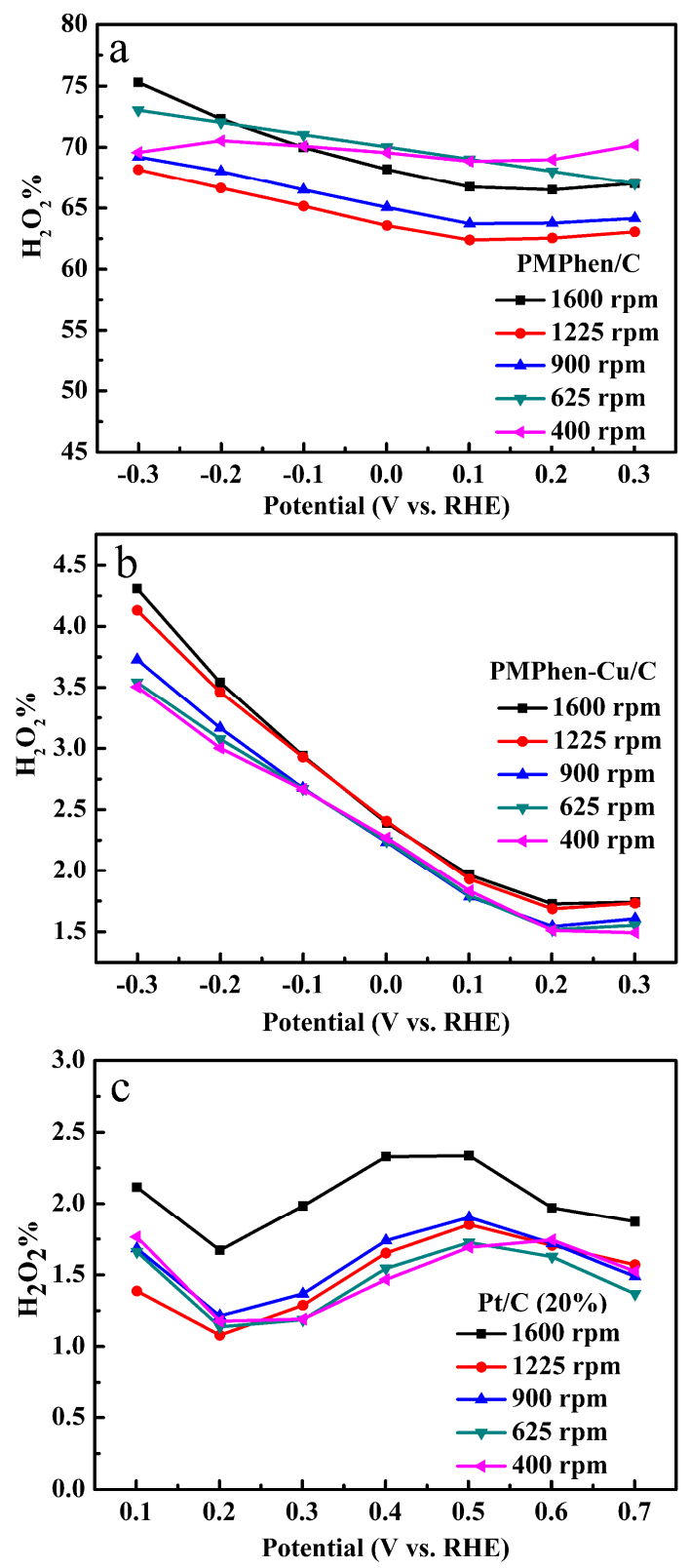

Figure 13. The yield of $\mathrm{H}_{2} \mathrm{O}_{2}$ of PMPhen/C (a), PMPhen-Cu/C (b), Pt/C (20\% Pt content) (c), respectively.

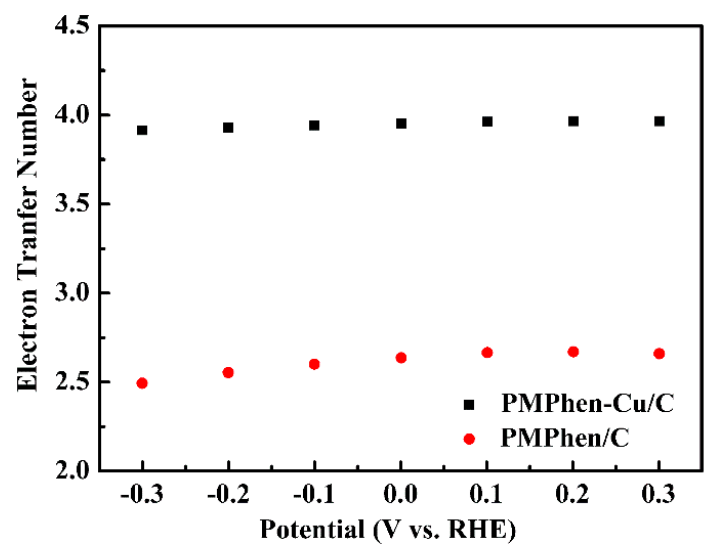

Figure 14. The electron transfer number (ENT) of PMPhen/C (red color) and PMPhen-Cu/C (black color). 
The kinetics of the two catalysts were further analyzed by the rotating ring-disk electrode (RRDE) data, which aimed to obtain the relation of the definite ORR mechanism (or pathway). The rate constants including $k_{1}, k_{2}$ and $k_{3}$ for each catalyst at different potentials could be estimated from the equations below (Equations (13)-(17)) [39,40]. The relationships of $-I_{d} / I_{r}$ vs. $\omega^{-1 / 2}$ were plotted and linear dependences simulated, and the obtained intercept and slope were the values of $\mathrm{I}_{1}$ and $\mathrm{S}_{1}$, respectively. The relationships of $I_{d l} /\left(I_{d l}-I_{d}\right)$ vs. $\omega^{-1 / 2}$ was also plotted and simulated, and $S_{2}$ was obtained as the slope obtained. $I_{d l}$ is the disk-limiting current, which was obtained from Equation (2).

$$
\begin{gathered}
\frac{I_{d}}{I_{r}}=\frac{1+2 k_{1} / k_{2}}{N}+\frac{2\left(1+k_{1} / k_{2}\right)}{N Z_{\mathrm{H}_{2} \mathrm{O}_{2}}} k_{3} \omega^{-1 / 2} \\
\frac{I_{d l}}{I_{d l}-I_{d}}=1+\frac{k_{1}+k_{2}}{Z_{\mathrm{O}_{2}}} \omega^{-1 / 2} \\
k_{1}=S_{2} Z_{\mathrm{O}_{2}} \frac{I_{1} N-1}{I_{1} N+1} \\
k_{2}=\frac{2 Z_{\mathrm{O}_{2}} S_{2}}{I_{1} N+1} \\
k_{3}=\frac{Z_{\mathrm{H}_{2} \mathrm{O}_{2}} N S_{1}}{I_{1} N+1} \\
Z_{\mathrm{H}_{2} \mathrm{O}_{2}}=0.62 D_{\mathrm{H}_{2} \mathrm{O}_{2}}^{2 / 3} v^{-1 / 6} \cdot Z_{\mathrm{O}_{2}}=0.62 D_{\mathrm{O}_{2}}^{2 / 3} v^{-1 / 6}
\end{gathered}
$$

$D_{\mathrm{H}_{2} \mathrm{O}_{2}}$ and $\mathrm{D}_{\mathrm{O}_{2}}$ are the diffusion coefficients of $\mathrm{H}_{2} \mathrm{O}_{2}$ and $\mathrm{O}_{2}$ in the PBS solution, respectively, which were $1.83 \times 10^{-5} \mathrm{~cm}^{2} \mathrm{~s}^{-1}$ and $1.9 \times 10^{-5} \mathrm{~cm}^{2} \mathrm{~s}^{-1}$, respectively. $v$ is the kinematic viscosity of $0.1 \mathrm{M}$ PBS solution, which was cited as $0.01 \mathrm{~cm}^{2} \mathrm{~s}^{-1}$ [24].

Figure 15a,b shows the $k_{1}, k_{2}$ and $k_{3}$ values of PMPhen/C and PMPhen-Cu/C at the potential range of $-0.3 \mathrm{~V}-0.3 \mathrm{~V}$. As shown in Figure 15a, the relative magnitude of the constant value is $k_{2}>k_{1}>>k_{3}$, which suggested the coexistence of two ORR pathways: one was the four-electron pathway and the other the two-electron pathway, with the former pathway playing a major role. The small $k_{3}$ value suggests that only a small portion of $\mathrm{H}_{2} \mathrm{O}_{2}$ produced in the two-electron pathway was reduced to water. In addition, it can be seen that $k_{2}, k_{3}$ were all potential dependent, while $k_{1}$ was independent of potential (Figure 15a), which explained the trend that the percentage of $\mathrm{H}_{2} \mathrm{O}_{2}$ was large in negative potential.

For the PMPhen- $\mathrm{Cu} / \mathrm{C}$ catalyst, as shown in Figure 15b, the relative magnitude of the constant value was $k_{1} \gg k_{2} \sim k_{3}$, which indicated that the predominant pathway was the direct four-electron ORR pathway with water as the final product [41,42]. Another phenomenon was the value of $k_{2}<k_{3}$, which meant that $\mathrm{H}_{2} \mathrm{O}_{2}$ produced in the two-electron pathway was immediately transformed to $\mathrm{H}_{2} \mathrm{O}$. Two consecutive reaction steps jointly finished the indirect four-electron process, which was consistent with the overall four-electron pathway of the PMPhen- $\mathrm{Cu} / \mathrm{C}$ catalyst presented in Figure 14.

In a word, PMPhen- $\mathrm{Cu} / \mathrm{C}$ had a comparable ORR catalytic activity as $\mathrm{Pt} / \mathrm{C}(20 \% \mathrm{Pt}$ content) in aqueous neutral medium, which was much higher than that of PMPhen/C. In the PMPhen/C catalyst, the pyridine nitrogen atoms may be the active sites responsible for its two-electron ORR pathway. As a comparison, the active sites for PMPhen- $\mathrm{Cu} / \mathrm{C}$ might be the $\mathrm{Cu}-\mathrm{N}_{x}$ units, which were responsible for the four-electron ORR pathway. The complexed copper ions were indispensable components for the pulse-on of the four-electron ORR pathway. Table 2 lists the ORR activities of some $\mathrm{M}-\mathrm{N}_{x}(\mathrm{M}=\mathrm{Cu}, \mathrm{Mn}$, $\mathrm{Co}, \mathrm{Fe}$ )-containing non-noble metal ORR catalyst and compares their performances in terms of some key parameters including $E_{\text {onset }}, E_{1 / 2}$ (half-wave potential), $\mathrm{n}$ and the $\mathrm{X}_{\mathrm{H} 2 \mathrm{O} 2}$ value. Among the Pt-free and $\mathrm{M}-\mathrm{N}_{x}$ containing catalysts (Table 2 ), the PMPhen- $\mathrm{Cu} / \mathrm{C}$ catalyst had a relatively high $\mathrm{n}$ value and a moderate $E_{\text {onset }}$ value and also had a very low $\mathrm{X}_{\mathrm{H} 2 \mathrm{O} 2}$ value. In view of its facile preparation method and wide source of raw materials, PMPhen- $\mathrm{Cu} / \mathrm{C}$ is expected to have potential applications in fuel cells operating in neutral aqueous solutions, such as microbial fuel cells. 

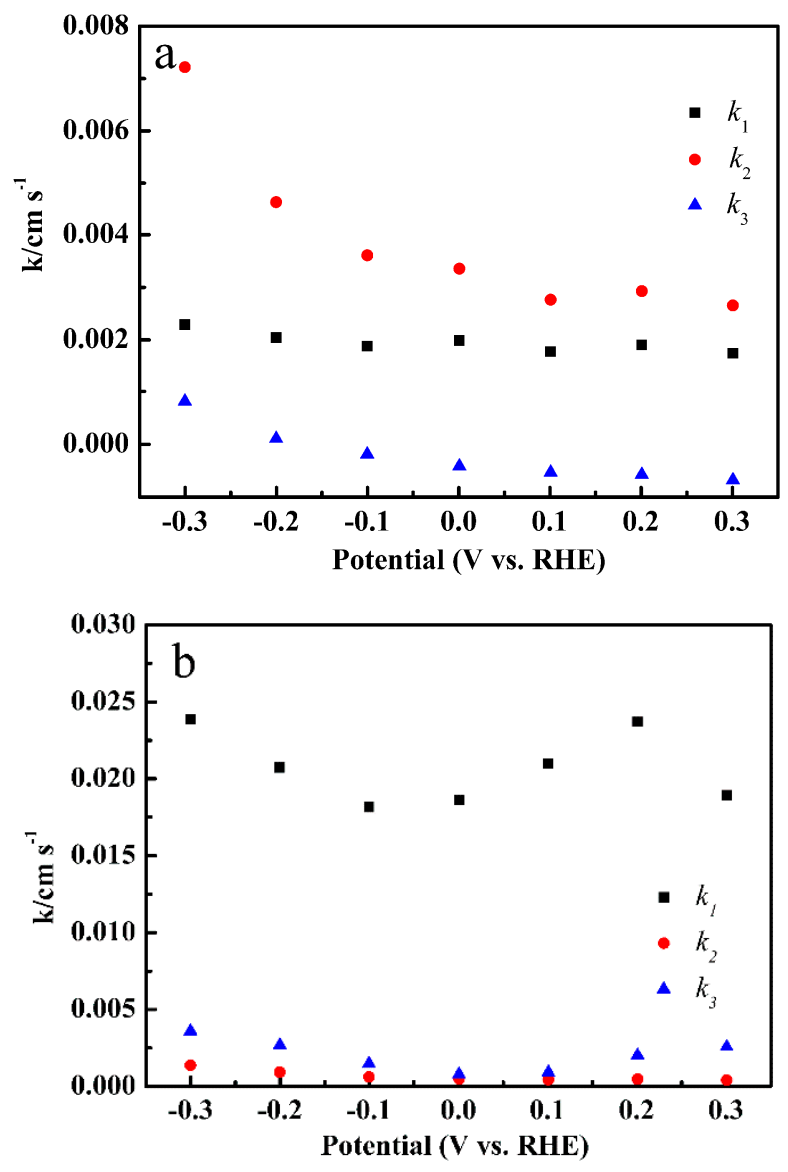

Figure 15. The value of $k_{1}, k_{2}, k_{3}$ of PMPhen/C (a) and PMPhen-Cu/C (b).

Table 2. ORR abilities of some $\mathrm{M}-\mathrm{N}_{x}$-containing non-noble catalysts reported in recent years.

\begin{tabular}{|c|c|c|c|c|c|c|c|}
\hline Catalyst & $E_{\text {onset }}(\mathrm{V})$ & $E_{1 / 2}(\mathrm{~V})$ & $\mathbf{n}$ & $\begin{array}{c}\text { Average } \\
\mathrm{H}_{2} \mathrm{O}_{2}(\%)\end{array}$ & $\begin{array}{l}\text { Electrolyte } \\
\text { Solution }\end{array}$ & $\begin{array}{l}\text { Reference } \\
\text { Electrode }\end{array}$ & Ref. \\
\hline PMPhen-Cu/C & 0.61 & 0.35 & 3.95 & $3.0 \%$ & PBS (pH = 7) & RHE & this study \\
\hline PMPhen/C & 0.45 & 0.33 & 2.35 & $71.5 \%$ & PBS (pH = 7) & RHE & this study \\
\hline $\mathrm{Pt} / \mathrm{C}(20 \% \mathrm{Pt}$ content $)$ & 0.90 & 0.63 & 4.0 & $1.6 \%$ & PBS (pH = 7) & RHE & this study \\
\hline $\mathrm{Cu}-\mathrm{SOCBP} / \mathrm{C}$ & 0.62 & 0.44 & 3.8 & $9 \%$ & $\mathrm{PBS}(\mathrm{pH}=7)$ & RHE & [12] \\
\hline $\mathrm{FeCl}_{3}(\mathrm{btaH})_{2}$ & 0.89 & 0.78 & 3.8 & $10 \%$ & $0.1 \mathrm{M} \mathrm{KOH}$ & RHE & [43] \\
\hline CuPPyPhen/C & 0.62 & - & 4.0 & $7.8 \%$ & PBS (pH = 7) & RHE & [25] \\
\hline FePPyPhen/C & 0.56 & - & 3.83 & $19.5 \%$ & PBS (pH = 7) & RHE & [25] \\
\hline Corrole-Co/MWCNT & 0.75 & 0.40 & 4.0 & - & $0.5 \mathrm{M} \mathrm{H}_{2} \mathrm{SO}_{4}$ & NHE & {$[44]$} \\
\hline$[\mathrm{Cu}(\mathrm{TPA})(\mathrm{L})]^{2+} / \mathrm{C}$ & 0.69 & 0.23 & 3.8 & - & $\begin{array}{l}\text { Britton-Robinson } \\
\text { buffer }(\mathrm{pH}=7)\end{array}$ & NHE & [45] \\
\hline $\mathrm{Cu}-\mathrm{CTF} / \mathrm{CPS}$ & 0.81 & - & 3.85 & - & PBS (pH = 7) & NHE & [46] \\
\hline $\mathrm{Cu}-\mathrm{HT} / \mathrm{Au}$ & 0.74 & - & 3.7 & - & $\begin{array}{l}\text { Britton-Robinson } \\
\text { buffer }(\mathrm{pH}=7)\end{array}$ & NHE & [47] \\
\hline
\end{tabular}

\section{Experimental Section}

\subsection{Materials}

PAMAM dendrimer solution in methanol (generation 4, $10 \mathrm{wt} \%$ ) was purchased from Aldrich China (Shanghai, China). 1,10-Phenanthroline-5-carboxylic acid, 1-(3-dimethylaminopropyl)- $N$ ethylcarbodiimide hydrochloride (EDAC) (AR, 98.5\%), N-hydroxysulfosuccinimide sodium salt (NHS) (AR, 98\%), Pt/C (20\% Pt content), Vulcan XC-72 carbon (BET surface area of $235 \mathrm{~m}^{2} \mathrm{~g}^{-1}$ ), 
$\mathrm{NaH}_{2} \mathrm{PO}_{4} \cdot 2 \mathrm{H}_{2} \mathrm{O}(\mathrm{AR}), \mathrm{Na}_{2} \mathrm{HPO}_{4} \cdot 12 \mathrm{H}_{2} \mathrm{O}(\mathrm{AR}), \mathrm{CuSO}_{4} \cdot 5 \mathrm{H}_{2} \mathrm{O}(\mathrm{AR})$, isopropanol (AR) and nafion $(5 \%)$ were all purchased from Aladdin Reagents Company (Shanghai, China) and be used without any further treatment. High pure-grade $\mathrm{O}_{2}$ and $\mathrm{N}_{2}$ were employed to prepare oxygen-free or oxygen-saturated buffer solutions for the test medium.

\subsection{Sample Preparation}

\subsubsection{Synthesis of PMPhen/C}

Carbon-supported PMPhen was synthesized through a modified way as follows: $0.5 \mathrm{~g}$ of Vulcan XC-72 carbon were dispersed in $50 \mathrm{~mL}$ of phosphate buffer $(\mathrm{pH}=5.0)$ to form a black carbon slurry, and this slurry was ultrasonicated under an ice bath for $1 \mathrm{~h}$. Then, $1 \mathrm{~mL}$ of PAMAM, $1 \mathrm{~g}$ of EDAC and $0.15 \mathrm{~g}$ of NHS were successively added to the carbon slurry at an interval time of $1 \mathrm{~h}$. After that, the reaction continued for another $30 \mathrm{~min}$, then $0.50 \mathrm{~g}$ of 1,10-Phenanthroline-5-carboxylic acid were put into the reaction mixture, and the reaction lasted for further $24 \mathrm{~h}$. Finally, the solid PMPhen/C composite was obtained by centrifugation and rinsed with ultrapure water several times, and the obtained composite was dried at $60^{\circ} \mathrm{C}$ in a vacuum oven. The synthetical step of PMPhen is shown in Scheme 1 [25].

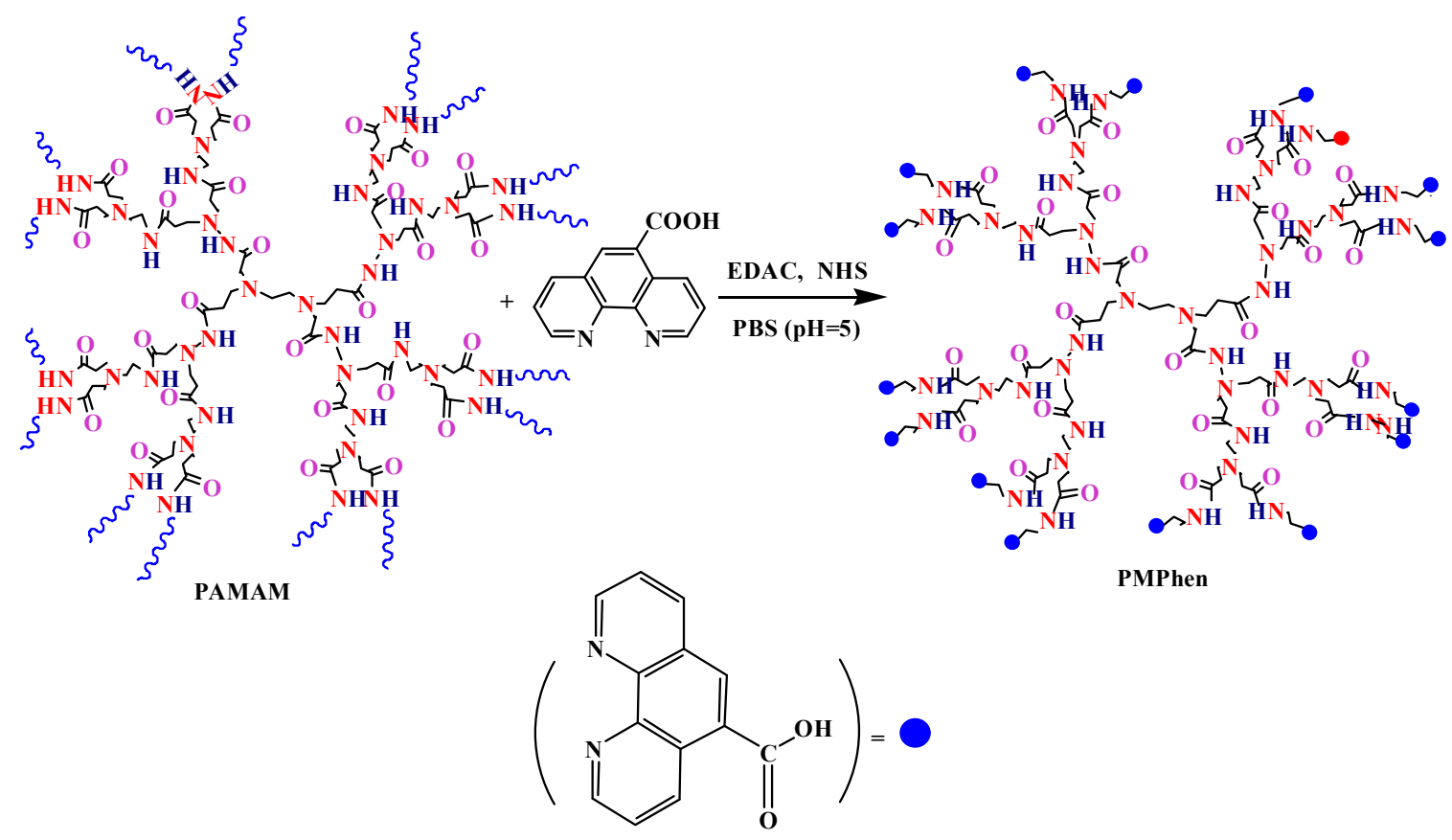

Scheme 1. Synthetical procedures for the PMPhen/C composite.

\subsubsection{Preparation of the Modified Electrode with PMPhen/C, PMPhen- $\mathrm{Cu} / \mathrm{C}$ and $\mathrm{Pt} / \mathrm{C}$ Catalysts}

A mixture slurry of PMPhen/C composite was prepared beforehand for the reparation of the modified glassy electrode. To achieve this aim, $3.2 \mathrm{mg}$ of PMPhen/C was uniformly dispersed in a solution that consisted of $177 \mu \mathrm{L}$ of iso-propanol, $3.5 \mu \mathrm{L}$ of nafion solution ( $5 \mathrm{wt} \%$ ) and $570 \mu \mathrm{L}$ of ultra-pure water, and the mixture was treated by ultrasonic treatment for $30 \mathrm{~min}$. Next, $8.5 \mu \mathrm{L}$ of the catalyst slurry were dropped on the freshly-cleaned surface of the glassy electrode and then dried at room temperature to form a uniform film. Prior to the modification of the glassy electrode, it was polished with $\mathrm{Al}_{2} \mathrm{O}_{3}(0.3 \mu \mathrm{m})$ suspension and ultrasonically cleaned in distilled water for $10 \mathrm{~min}$ [26]. The PMPhen- $\mathrm{Cu} / \mathrm{C}$ glassy carbon electrode was prepared by means of submerging the PMPhen/C modified glassy electrode in $10 \mathrm{mM} \mathrm{CuSO}_{4}$ solution for $3 \mathrm{~h}$, then the surface was gently rinsed with ultra-pure water several times and dried at room temperature. The method for the preparation of the 
$\mathrm{Pt} / \mathrm{C}$ (20\% Pt content) modified electrode was identical to that of PMPhen/C, the difference being that $3.2 \mathrm{mg}$ of $\mathrm{Pt} / \mathrm{C}(20 \% \mathrm{Pt}$ content) catalyst were used to replace the PMPhen/C to make the catalyst slurry, and $11 \mu \mathrm{L}$ of the slurry were dropped on the cleaned glassy electrode.

\subsection{Physical Characterization}

The surface microstructure and elemental composition were analyzed by scanning electron microscopy (SEM, SU 8020, Carl Zeiss Ltd., Oberkochen, Germany) and X-ray photoelectron spectroscopy (XPS, ESCALAB 250Xi, Thermo Fisher Scientific Inc., Waltham, MA, USA), respectively. The catalyst slurry was dropped on the indium tin oxide (ITO)-coated glass sheet to form a uniform layer of catalyst film, which was used as the sample for scanning electron microscopy (SEM) and X-ray photoelectron spectroscopy (XPS) measurements. The PMPhen-Cu/ITO film was prepared by dipping the PMPhen/ITO film in $10 \mathrm{mM} \mathrm{CuSO}_{4}$ solution for $3 \mathrm{~h}$, and then the non-complexed copper ions were removed by washing with deionized water [48].

\subsection{Electrochemical Measurement}

The electrochemical properties of the catalysts were evaluated by cyclic voltammetry (CV), linear sweep voltammetry (LSV) and rotating ring disk electrode (RRDE) methods. The measurements were conducted with a computer-controlled Autolab potentiostat/galvanostat (PGSTAT302N, Metrohm Autolab, The Netherlands) with an electrode rotator (AFMSRCE, Pine, Phychemi Company, Hongkong, China). A standard three-electrode electrochemical system was constructed using the catalyst-modified electrode as the working electrode, the $\mathrm{Ag} / \mathrm{AgCl}\left(0.197 \mathrm{~V}+0.0591 \times \mathrm{pH}\right.$ vs. $\mathrm{RHE}$ at $\left.25^{\circ} \mathrm{C}\right)$ electrode as the reference electrode and a platinum wire (diameter, $1 \mathrm{~mm}$ ) as the counter electrode. The working electrode applied for cyclic voltammetry (CV) and rotating disk electrode (RDE) measurements was a glassy carbon electrode with a diameter of $5 \mathrm{~mm}$ (AFMSRCE, Pine, Phychemi Company, Hongkong, China), and for the rotating ring disk electrode (RRDE) measurements, the working electrode was a rotating ring-disk electrode (AFE7R9GCPT, Pine, Phychemi Company, Hongkong, China) with a rotating glassy carbon disk (diameter, $5.61 \mathrm{~mm}$ ) and a platinum ring (outer diameter 7.92; inner diameter $6.25 \mathrm{~mm}$ ). The supporting electrolyte used was $0.1 \mathrm{M}$ phosphate buffer solution (PBS), which was saturated with $\mathrm{O}_{2}$ or $\mathrm{N}_{2}$ according to the analysis requirements of the cyclic voltammetry (CV), rotating disk electrode (RDE) and rotating ring disk electrode (RRDE) measurements. A gas bubbling time of $30 \mathrm{~min}$ was required to achieve the saturated state at $1 \mathrm{~atm}$ [47]. For the CV measurement, the sweep rate was fixed at $100 \mathrm{mV} / \mathrm{s}$, and for the LSV measurement, the sweep rate was fixed at $10 \mathrm{mV} / \mathrm{s}$ [49].

\section{Conclusions}

In this paper, carbon powder, PAMAM dendrimers and 1,10-phenanthroline-5-carboxylic acid were used to prepare the PMPhen/C catalyst, with the latter two materials being covalently linked together and then loaded on the carbon powder materials. Upon the complexation of copper ions to the PMPhen $/ \mathrm{C}$ catalyst, the PMPhen- $\mathrm{Cu} / \mathrm{C}$ catalyst was formed, which had the $\mathrm{Cu}-\mathrm{N}_{x}$ units. The structures and the elemental composition of the catalysts were analyzed by scanning electron microscopy (SEM), Brunner-Emmet-Teller (BET) and the X-ray photoelectron spectroscopy (XPS) methods. The electrochemical analyses including rotating disk electrode (RDE) and rotating ring disk electrode (RRDE) measurements showed that both of the catalysts had ORR activities, and the catalyst PMPhen/C took the two-electron pathway, while the catalyst PMPhen- $\mathrm{Cu} / \mathrm{C}$ took the four-electron pathway in the ORR process. A more accurate ORR pathway analysis pathway was undertaken by calculating the rate constants of the related reactions involved in the ORR process. The ORR pathways of the two catalysts were analyzed and compared based on the $\mathrm{k}$ values, which showed that the $\mathrm{Cu}-\mathrm{N}_{x}$ unit might be responsible for the direct conversion of oxygen to water for the PMPhen- $\mathrm{Cu} / \mathrm{C}$ catalyst, and the ORR process could be explained by the mono-Cu reaction mechanism. 
Supplementary Materials: The following are available online at http:/ /www.mdpi.com/2073-4344/8/6/245/s1: Figure S1: LSV of Pt/C (20\%) at different rotating speed in oxygen saturated electrolyte, Figure S2: K-L plots of $\mathrm{Pt} / \mathrm{C}$ at the potential of $0.2 \mathrm{~V}, 0.3 \mathrm{~V}$ and $0.4 \mathrm{~V}$.

Author Contributions: Y.C. synthesized and characterized the catalysts and drafted the manuscript. L.G. took the XPS measurements. X.J. analyzed the data and provided some analytical software. H.D. guided the electrochemical experiments. J.Z. supervised the work and critically revised the manuscript. K.Q. provided the idea of the manuscript.

Acknowledgments: The work was financially supported by the National Natural Science Foundation of China (51473074, 21601079) and Natural Foundation of Shandong Province (ZR2016EMQ06).

Conflicts of Interest: The authors declare no conflict of interest.

\section{References}

1. Yang, Z.K.; Lin, L.; Liu, Y.N.; Zhou, X.; Yuan, C.Z.; Xu, A.W. Supramolecular polymers-derived nonmetal N, S-codoped carbon nanosheets for efficient oxygen reduction reaction. RSC Adv. 2016, 6, 52937-52944. [CrossRef]

2. Zhao, Y.W.; Zhang, L.Q.; Wei, W.; Li, Y.; Liu, A.R.; Zhang, Y.J.; Liu, S.Q. Effect of annealing temperature and element composition of titanium dioxide/graphene/hemin catalysts for oxygen reduction reaction. RSC Adv. 2015, 5, 82879-82886. [CrossRef]

3. Tran, T.N.; Song, M.Y.; Singh, K.P.; Yang, D.S.; Yu, J.S. Iron-polypyrrole electrocatalyst with remarkable activity and stability for ORR in both alkaline and acidic conditions: A comprehensive assessment of catalyst preparation sequence. J. Mater. Chem. A 2016, 4, 8645-8657. [CrossRef]

4. Nallathambi, V.; Lee, J.W.; Kumaraguru, S.P.; Wu, G.; Popov, B.N. Development of high performance carbon composite catalyst for oxygen reduction reaction in PEM proton exchange membrane fuel cells. J. Power Sources 2008, 183, 34-42. [CrossRef]

5. Yadav, R.M.; Wu, J.J.; Kochandra, R.; Ma, L.L.; Tiwary, C.S.; Ge, L.H.; Ye, G.L.; Vajtai, R.; Lou, J.; Ajayan, P.M. Carbon nitrogen nanotubes as efficient bifunctional electrocatalysts for oxygen reduction and evolution reactions. ACS. Appl. Mater. Interfaces 2015, 7, 11991-12000. [CrossRef] [PubMed]

6. Gong, Y.J.; Fei, H.L.; Zou, X.L.; Zhou, W.; Yang, S.B.; Ye, G.L.; Liu, Z.; Peng, Z.W.; Lou, J.; Vajtai, R.; et al. Boron and nitrogen-substituted graphene nanoribbons as efficient catalysts for oxygen reduction reaction. Chem. Mater. 2015, 27, 1181-1186. [CrossRef]

7. Raj, C.R.; Samanta, A.; Noh, S.H.; Mondal, S.; Okajima, T.; Ohsaka, T. Emerging new generation electrocatalysts for oxygen reduction reaction. J. Mater. Chem. A 2016, 4, 11156-11178. [CrossRef]

8. Yan, Z.H.; Wang, M.; Liu, J.F.; Liu, R.M.; Zhao, J.S. Glycerol-stabilized $\mathrm{NaBH}_{4}$ reduction at room-temperature for the synthesis of a carbon-supported $\mathrm{Pt}_{\mathrm{x}} \mathrm{Fe}$ alloy with superior oxygen reduction activity for a microbial fuel cell. Electrochim. Acta 2014, 141, 331-339. [CrossRef]

9. Jung, W.S. High-performance bimetallic alloy catalyst using Ni and N co-doped composite carbon for the oxygen reduction electro-reduction. J. Colloid Interface Sci. 2018, 514, 30-39. [CrossRef] [PubMed]

10. Gu, W.L.; Hu, L.Y.; Li, J.; Wang, E. Hybrid of g- $\mathrm{C}_{3} \mathrm{~N}_{4}$ Assisted metal-organic frameworks and their derived high-efficiency oxygen reduction electrocatalyst in the whole $\mathrm{pH}$ range. ACS Appl. Mater. Interfaces 2016, 8, 35281-35288. [CrossRef] [PubMed]

11. Lei, H.T.; Liu, C.Y.; Wang, Z.J.; Zhang, Z.Y.; Zhang, M.N.; Chang, X.M.; Zhang, W.; Cao, R. Noncovalent immobilization of a pyrene-modified cobalt corrole on carbon supports for enhanced electrocatalytic oxygen reduction and oxygen evolution in aqueous solutions. ACS Catal. 2016, 6, 6429-6437. [CrossRef]

12. Zhao, Y.Y.; Chu, Y.; Ju, X.P.; Zhao, J.S.; Kong, L.Q.; Zhang, Y. Carbon-supported copper-based nitrogen-containing supramolecule as an efficient oxygen reduction reaction catalysts in neutral medium. Catalysts 2018, 8, 53. [CrossRef]

13. Muthukrishnan, A.; Nabae, Y.; Hayakawa, T.; Okajima, T.; Ohsaka, T. Fe-containing polyimide-based high-performance ORR catalysts in acidic medium: A kinetic approach to study the durability of catalysts. Catal. Sci. Technol. 2015, 5, 475-483. [CrossRef]

14. Wang, L.; Zheng, Y.L.; Lu, X.P.; Li, Z.; Sun, L.L.; Song, Y.H. Dendritic copper-cobalt nanostructures/reduced graphene oxide-chitosan modified glassy carbon electrode for glucose sensing. Sens. Actuators B Chem. 2014, 195, 1-7. [CrossRef] 
15. Gong, K.; Du, F.; Xia, Z.; Durstock, M.; Dai, L. Nitrogen-doped carbon nanotube arrays with high electrocatalytic activity for oxygen reduction. Science 2009, 323, 760-764. [CrossRef] [PubMed]

16. Alreja, P.; Kaur, N. Recent advances in 1, 10-phenanthroline ligands for chemosensing of cations and anions. RSC Adv. 2016, 6, 23169-23217. [CrossRef]

17. Lin, L.; Li, M.; Jiang, L.; Li, Y.; Liu, D.; He, X.; Cui, L. A novel iron (II) polyphthalocyanine catalyst assembled on graphene with significantly enhanced performance for oxygen reduction reaction in alkaline medium. J. Power Sources 2014, 268, 269-278. [CrossRef]

18. Hyun, K.; Lee, J.H.; Yoon, C.W.; Cho, Y.H.; Kim, L.H.; Kwon, Y. Improvement in oxygen reduction activity of polypyrrole-coated PtNi alloy catalyst prepared for proton exchange membrane fuel cells. Synth. Met. 2014, 190, 48-55. [CrossRef]

19. Canales, C.; Ramírez, G. Glassy carbon electrodes modified with supramolecular assemblies generated by $\pi$-stacking of Cobalt (II) octaethylporphyrins. A 4 electrons-dioxygen reduction reaction occurring at positive potentials. Electrochim. Acta 2015, 173, 636-641. [CrossRef]

20. Artyushkova, K.; Serov, A.; Rojas-Carbonell, S.; Atanassov, P. Chemistry of multitudinous active sites for oxygen reduction reaction in transition metal-nitrogen-carbon electrocatalysts. J. Phys. Chem. C 2015, 119, 25917-25928. [CrossRef]

21. Ding, W.; Wei, Z.D.; Chen, S.G.; Qi, X.Q.; Yang, T.; Hu, J.S.; Wang, D.; Wang, L.J.; Alvi, S.F.; Li, L. Space-Confinement-Induced Synthesis of Pyridinic- and Pyrrolic-Nitrogen-Doped Graphene for the Catalysis of Oxygen Reduction. Angew. Chem. Int. Ed. 2013, 52, 11755-11759. [CrossRef] [PubMed]

22. Zhang, L.P.; Niu, J.B.; Dai, L.M.; Xia, Z.H. Effect of microstructure of nitrogen-doped graphene on oxygen reduction activity in fuel cells. Langmuir 2012, 28, 7542-7550. [CrossRef] [PubMed]

23. Guo, D.; Shibuya, R.; Akiba, C.; Saji, S.; Kondo, T.; Nakamura, J. Active sites of nitrogen-doped carbon materials for oxygen reduction reaction clarified using model catalysts. Science 2016, 351, 361-365. [CrossRef] [PubMed]

24. He, H.Y.; Wang, M.; Zhang, Y.; Zhao, J.S. Soluble conjugated polymer enriched with pyridinic nitrogen and its application as high-performance catalyst for oxygen reduction. J. Solid. State Electrochem. 2017, 21, 1639-1651. [CrossRef]

25. Lu, Y.; Wang, X.L.; Wang, M.; Kong, L.Q.; Zhao, J.S. 1,10-phenanthroline metal complex covalently bonding to poly-(pyrrole-3-carboxylic acid)-coated carbon: An efficient electrocatalyst for oxygen reduction. Electrochim. Acta 2015, 180, 86-95. [CrossRef]

26. He, H.Y.; Wang, M.; Zhao, J.S.; Zhang, Y. Poly(10,12-bis(4-hexylthiophen-2-yl)thieno[ $\left[3^{\prime}, 4^{\prime}: 5,6\right]$ pyrazino $[2,3-f][1,10]-$ phenanthroline)-copper(II) complex(II) complex as an efficient electrocatalyst for oxygen reduction. Chem. Eng. J. 2017, 316, 680-691. [CrossRef]

27. Ye, H.; Crooks, J.A.; Crooks, R.M. Effect of particle size on the kinetics of the electrocatalytic oxygen reduction reaction catalyzed by Pt dendrimer-encapsulated nanoparticles. Langmuir 2007, 23, 11901-11906. [CrossRef] [PubMed]

28. Briggs, D.; Beamson, G. XPS studies of the oxygen 1s and 2s levels in a wide range of functional polymers. Anal. Chem. 1993, 65, 1517-1523. [CrossRef]

29. Marletta, G.; Iacona, F.; Toth, A. Particle beam-induced reactions versus thermal degradation in PMDA-ODA polyimide. Macromolecules 1992, 25, 3190-3198. [CrossRef]

30. Martínez, J.M.L.; Rodríguez-Castellón, E.; Sánchez, R.M.T.; Denaday, L.R.; Buldain, G.Y.; Dall'Orto, V.C. XPS studies on the $\mathrm{Cu}$ (I, II)-polyampholyte heterogeneous catalyst: An insight into its structure and mechanism. J. Mol. Catal. A Chem. 2011, 339, 43-51. [CrossRef]

31. Yang, L.; Su, Y.; Li, W.; Kan, X. Fe/N/C Electrocatalysts for Oxygen Reduction Reaction in PEM Fuel Cells Using Nitrogen-Rich Ligand as Precursor. J. Phys. Chem. C 2015, 119, 11311-11319. [CrossRef]

32. Ferrandon, M.; Kropf, A.J.; Myers, D.J.; Artyushkova, K.; Kramm, U.; Bogdanoff, P.; Wu, G.; Johnston, C.M.; Zelenay, P. Multitechnique characterization of a polyaniline-iron-carbon oxygen reduction catalyst. J. Phys. Chem. C 2012, 116, 16001-16013. [CrossRef]

33. Wang, J.; Wang, K.; Wang, F.B.; Xia, X.H. Bioinspired copper catalyst effective for both reduction and evolution of oxygen. Nat. Commun. 2014, 5. [CrossRef] [PubMed]

34. Yu, J.F.; Lu, Y.Q.; Yuan, C.G.; Zhao, J.S.; Wang, M.; Liu, R.M. Carbon supported polyindole-5-carboxylic acid covalently bonded with pyridine-2, 4-diamine copper complex as a non-precious oxygen reduction catalyst. Electrochim. Acta 2014, 143, 1-9. [CrossRef] 
35. McCrory, C.C.; Devadoss, A.; Ottenwaelder, X.; Lowe, R.D.; Stack, T.D.P.; Chidsey, C.E. Electrocatalytic $\mathrm{O}_{2}$ reduction by covalently immobilized mononuclear copper (I) complexes: Evidence for a binuclear $\mathrm{Cu}_{2} \mathrm{O}_{2}$ intermediate. J. Am. Chem. Soc. 2011, 133, 3696-3699. [CrossRef] [PubMed]

36. Saracini, C.; Ohkubo, K.; Suenobu, T.; Meyer, G.J.; Karlin, K.D.; Fukuzumi, S. Laser-induced dynamics of peroxodicopper (II) complexes vary with the ligand architecture. One-photon two-electron $\mathrm{O}_{2}$ ejection and formation of mixed-valent $\mathrm{Cu}^{\mathrm{I}} \mathrm{Cu}^{\mathrm{II}}$-superoxide intermediates. J. Am. Chem. Soc. 2015, 137, 15865-15874. [CrossRef] [PubMed]

37. Lee, K.; Zhang, L.; Lui, H.S.; Hui, R.; Shi, Z.; Zhang, J.J. Oxygen reduction reaction (ORR) catalyzed by carbon-supported cobalt polypyrrole (Co-PPy/C) electrocatalysts. Electrochim. Acta 2009, 54, 4704-4711. [CrossRef]

38. McCrory, C.C.L.; Ottenwaelder, X.; Stack, T.D.P.; Chidsey, C.E.D. Kinetic and mechanistic studies of the electrocatalytic reduction of $\mathrm{O}_{2}$ to $\mathrm{H}_{2} \mathrm{O}$ with mononuclear $\mathrm{Cu}$ complexes of substituted 1,10-phenanthrolines. J. Phys. Chem. A 2007, 111, 12641-12650. [CrossRef] [PubMed]

39. Wu, J.J.; Zhang, D.; Niwa, H.; Harada, Y.; Oshima, M.; Ofuchi, H.; Nabae, Y.; Okajima, T.; Ohsaka, T. Enhancement in kinetics of the oxygen reduction reaction on a nitrogen-doped carbon catalyst by introduction of iron via electrochemical methods. Langmuir 2015, 31, 5529-5536. [CrossRef] [PubMed]

40. Muthukrishnan, A.; Nabae, Y.; Okajima, T.; Ohsaka, T. Kinetic approach to investigate the mechanistic pathways of oxygen reduction reaction on Fe-Containing N-doped carbon catalysts. ACS Catal. 2015, 5, 5194-5202. [CrossRef]

41. Olson, T.S.; Pylypenko, S.; Fulghum, J.E.; Atanassov, P. Bifunctional oxygen reduction reaction mechanism on non-platinum catalysts derived from pyrolyzed porphyrins. J. Electrochem. Soc. 2010, 157, 54-63. [CrossRef]

42. Muthukrishnan, A.; Nabae, Y. Estimation of the inherent kinetic parameters for oxygen reduction over a pt-free cathode catalyst by resolving the quasi-four-electron reduction. J. Phys. Chem. C 2016, 120, 22515-22525. [CrossRef]

43. Sheelam, A.; Ramanujam, K. Iron (III) chloride-benzotriazole adduct for oxygen reduction reaction in alkaline medium. Int. J. Hydrogen Energy 2018, 43, 4754-4762. [CrossRef]

44. Ou, Z.P.; Lü, A.X.; Meng, D.Y.; Huang, S.; Fang, Y.Y.; Lu, G.F.; Kadish, K.M. Molecular oxygen reduction electrocatalyzed by meso-substituted cobalt corroles coated on edge-plane pyrolytic graphite electrodes in acidic media. Inorg. Chem. 2012, 51, 8890-8896. [CrossRef] [PubMed]

45. Thorseth, M.A.; Letko, C.S.; Tse, E.C.M.; Rauchfuss, T.B.; Gewirth, A.A. Ligand effects on the overpotential for dioxygen reduction by tris(2-pyridylmethyl) amine derivatives. Inorg. Chem. 2013, 52, 628-634. [CrossRef] [PubMed]

46. Iwase, K.; Yoshioka, T.; Nakanishi, S.; Hashimoto, K.; Kamiya, K. Copper-modified covalent trizazine frameworks as non-noble-metal electrocatalysts for oxygen reduction. Angew. Chem. Int. Ed. 2015, 54, 11068-11072. [CrossRef] [PubMed]

47. Kato, M.; Oyaizu, N.; Shimazu, K.; Yagi, I. Oxygen reduction reaction catalyzed by self-assembled monolayers of copper-based electrocatalysts on a polycrystalline gold surface. J. Phys. Chem. C 2016, 120, 15814-15822. [CrossRef]

48. Thippani, T.; Mandal, S.; Wang, G.; Ramani, V.K.; Kothandaraman, R. Probing oxygen reduction and oxygen evolution reactions on bifunctional non-precious metal catalysts for metal-air batteries. RSC Adv. 2016, 6, 71122-71133. [CrossRef]

49. Malko, D.; Lopes, T.; Symianakis, E.; Kucernak, A.R. The intriguing poison tolerance of non-precious metal oxygen reduction reaction (ORR) catalysts. J. Mater. Chem. A 2016, 4, 142-152. [CrossRef]

(C) 2018 by the authors. Licensee MDPI, Basel, Switzerland. This article is an open access article distributed under the terms and conditions of the Creative Commons Attribution (CC BY) license (http://creativecommons.org/licenses/by/4.0/). 